Supporting Information

\title{
Thermocleavage of Partial Side Chains in Polythiophenes Offers Appreciable Photovoltaic Efficiency and Significant Morphological Stability
}

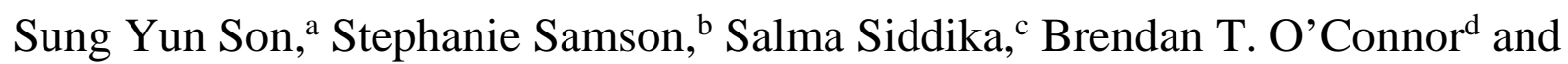
Wei You*a

${ }^{a}$ Department of Chemistry, University of North Carolina at Chapel Hill, Chapel Hill, NC 27599, United States

${ }^{b}$ Department of Applied Physical Sciences, University of North Carolina at Chapel Hill, Chapel Hill, NC 27599, United States

'Department of Materials Science and Engineering and Organic and Carbon Electronics Laboratories (ORaCEL), North Carolina State University, Raleigh, NC 27695, United States

${ }^{\mathrm{d} D e p a r t m e n t ~ o f ~ M e c h a n i c a l ~ a n d ~ A e r o s p a c e ~ E n g i n e e r i n g ~ a n d ~ O r g a n i c ~ a n d ~ C a r b o n ~}$ Electronics Laboratories (ORaCEL), North Carolina State University, Raleigh, NC 27695, United States

E-mail:wyou@unc.edu 


\section{Detailed synthetic procedures}

- Synthesis of P3ET via Grignard metathesis (GRIM) polymerization

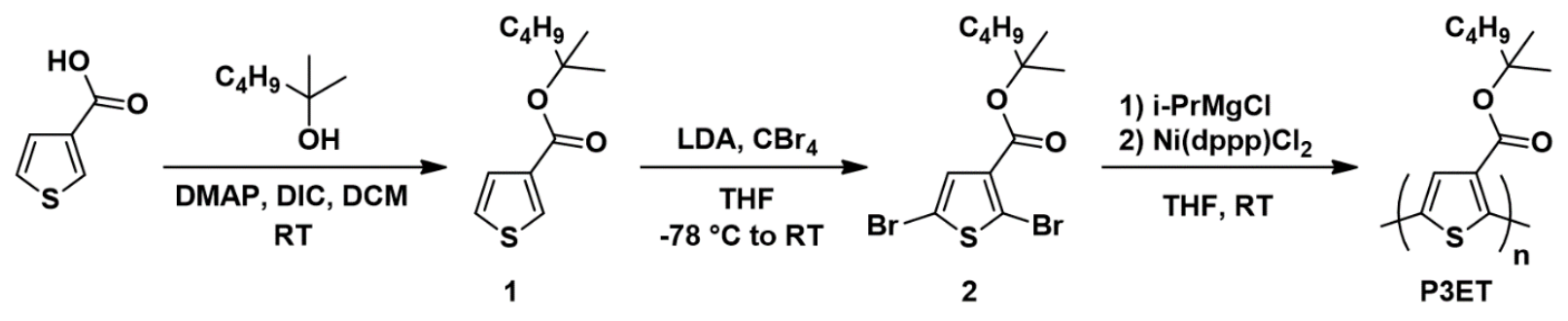

2-Methylhexan-2-yl thiophene-3-carboxylate (1). A mixture of thiophene-3-carboxylic acid (3.0 g, $23.41 \mathrm{mmol}$ ), 2-methyl-2-hexanol (3.26 g, $28.09 \mathrm{mmol}$ ) and 4-dimethylaminopyridine (DMAP) (572 mg, $4.68 \mathrm{mmol})$ in dichloromethane (DCM) $(100 \mathrm{~mL})$ was stirred at room temperature. After $15 \mathrm{~min}, N, N^{\prime}$-diisopropylcarbodiimide (DIC) $(4.03 \mathrm{~mL}, 25.75 \mathrm{mmol}$ ) was added and the reaction was stirred for 2 days. The reaction was passed through pad of silica eluting with DCM to remove the urea by-product and concentrated under vacuum. The crude was then purified by silica gel column chromatography eluted with hexane:DCM (gradient 0-10\% DCM), affording the product as a colorless liquid (3.82 g, $16.86 \mathrm{mmol}, 72 \%) .{ }^{1} \mathrm{H}$ NMR (400 $\left.\mathrm{MHz}, \mathrm{CDCl}_{3}, \mathrm{ppm}\right): \delta=8.00(\mathrm{dd}$, $J=3.1,1.2 \mathrm{~Hz}, 1 \mathrm{H}$ ), 7.46 (dd, $J=5.0,1.2 \mathrm{~Hz}, 1 \mathrm{H}), 7.26$ (dd, $J=5.0,3.1 \mathrm{~Hz}, 1 \mathrm{H}), 1.85$ (t, $J=7.8$ $\mathrm{Hz}, 2 \mathrm{H}), 1.55$ (s, 6H), 1.31-1.40 (m, 4H), 0.92 (t, $J=7.0 \mathrm{~Hz}, 3 \mathrm{H})$.

2-Methylhexan-2-yl 2,5-dibromothiophene-3-carboxylate (2). Compound 1 (500 mg, $2.21 \mathrm{mmol}$ ) was added to a two-neck round bottom flask which was subsequently evacuated and refilled three times with argon. Anhydrous THF $(5 \mathrm{~mL})$ was added and the reaction flask was cooled to $-78^{\circ} \mathrm{C}$. Lithium diisopropylamide (LDA) (2M in THF/heptane/ethylbenzene, $2.32 \mathrm{~mL}, 4.64 \mathrm{mmol}$ ) was added dropwise and the reaction was stirred for $1 \mathrm{~h}$ at $-78^{\circ} \mathrm{C}$. To the reaction, carbon tetrabromide $\left(\mathrm{CBr}_{4}\right)(1.54 \mathrm{~g}, 4.64 \mathrm{mmol})$ in anhydrous THF $(5 \mathrm{~mL})$ was added. After $30 \mathrm{~min}$ at $-78{ }^{\circ} \mathrm{C}$, the reaction was allowed to warm to room temperature and stirred overnight at room temperature. The solvent was removed under reduced pressure. The crude was purified through silica gel column chromatography with hexane:DCM = 10:1 as eluent. Yielded a colorless liquid (5.53 mg, 1.44 mmol, $65 \%$ ). ${ }^{1} \mathrm{H}$ NMR (400 MHz, $\mathrm{CDCl}_{3}, \mathrm{ppm}$ ): $\delta=7.27$ (s, $\left.1 \mathrm{H}\right), 1.85$ (t, $\left.J=7.8 \mathrm{~Hz}, 2 \mathrm{H}\right), 1.55$ (s, 6H), 1.31-1.40 (m, 4H), $0.92(\mathrm{t}, J=7.0 \mathrm{~Hz}, 3 \mathrm{H})$.

GRIM polymerization for P3ET synthesis. Compound 2 (192 $\mathrm{mg}, 0.5 \mathrm{mmol})$ was added to a twoneck round bottom flask which was subsequently evacuated and refilled three times with argon. Then, anhydrous THF ( $5 \mathrm{~mL}$ ) was added. $2 \mathrm{M}$ of isopropylmagnesium chloride in THF ( $0.25 \mathrm{~mL}$, $0.5 \mathrm{mmol}$ ) was added, and the reaction mixture was stirred for $1 \mathrm{~h}$ at room temperature. Then, $\mathrm{Ni}(\mathrm{dppp}) \mathrm{Cl}_{2}$ (2 $\mathrm{mg}, 0.0037 \mathrm{mmol}$ ) dispersed in THF $(5 \mathrm{~mL}$ ) was added and the reaction mixture was stirred overnight. The reaction was quenched by adding $\mathrm{MeOH}$. However, no polymer was obtained. It was observed that protonation predominantly occurred at the 2-position of compound 2 by characterizing the reaction mixture after quenching via NMR (Figure S1). 


\section{- Synthesis of P3ET via direct arylation polymerization (DArP)}
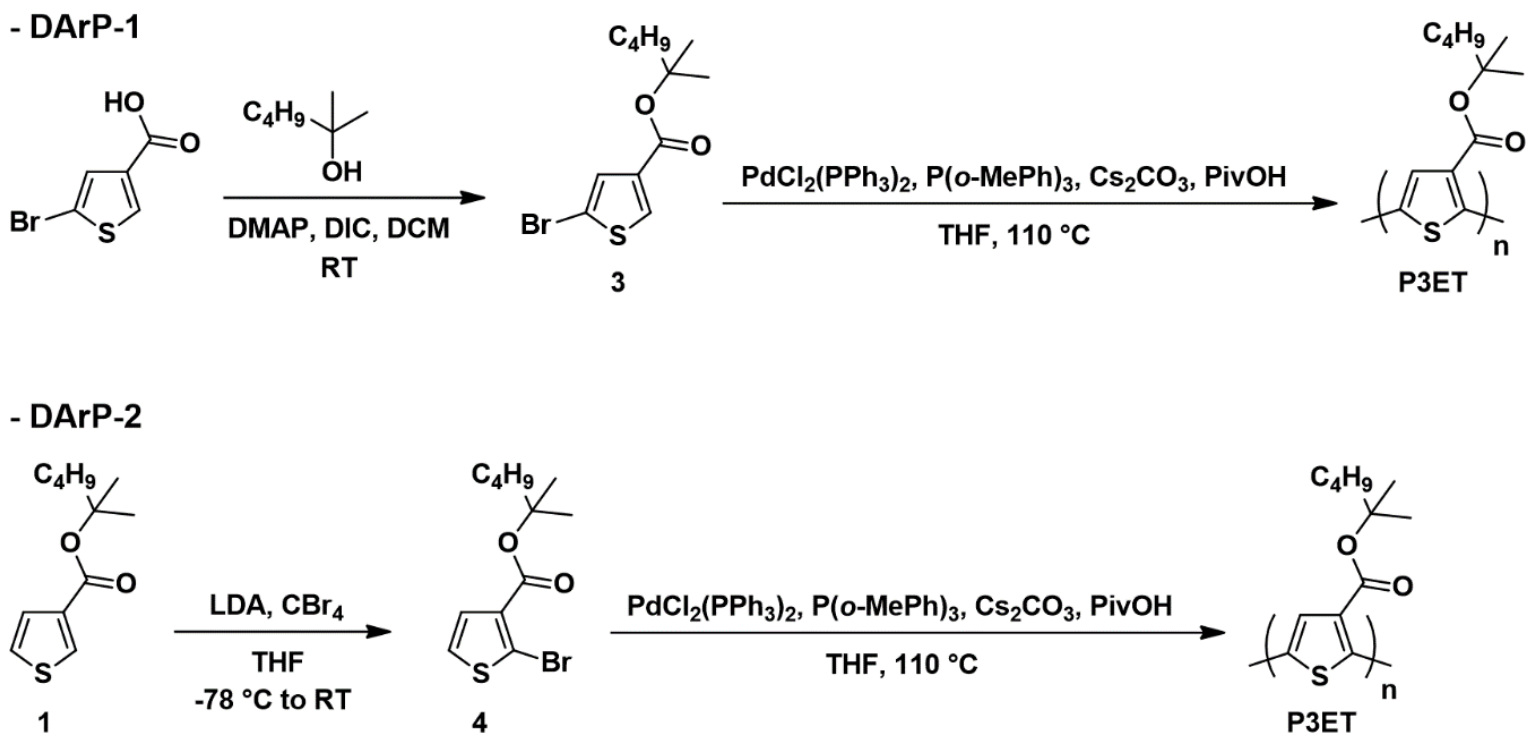

2-Methylhexan-2-yl 5-bromothiophene-3-carboxylate (3). A mixture of 5-bromothiophene-3carboxylic acid (5.0 g, $24.15 \mathrm{mmol}$ ), 2-methyl-2-hexanol (3.54 g, $28.98 \mathrm{mmol}$ ) and DMAP (561 $\mathrm{mg}, 4.83 \mathrm{mmol})$ in DCM (70 mL) was stirred at room temperature. After $15 \mathrm{~min}$, DIC (4.11 mL, $26.57 \mathrm{mmol}$ ) was added. The reaction was stirred for 2 days. The reaction was passed through pad of silica eluting with DCM to remove the urea by-product and concentrated under vacuum. The crude was then purified by silica gel column chromatography eluted with hexane:DCM (gradient 0-10\% DCM), affording the product as a colorless liquid (6.0 g, $19.66 \mathrm{mmol}, 81 \%) .{ }^{1} \mathrm{H}$ NMR (400 $\left.\mathrm{MHz}, \mathrm{CDCl}_{3}, \mathrm{ppm}\right): \delta=7.89(\mathrm{~d}, J=1.5 \mathrm{~Hz}, 1 \mathrm{H}), 7.39$ (d, $\left.J=1.5 \mathrm{~Hz}, 1 \mathrm{H}\right), 1.83(\mathrm{t}, J=7.8 \mathrm{~Hz}, 2 \mathrm{H})$, 1.53 (s, 6H), 1.31-1.40 (m, 4H), 0.91 (t, $J=7.0 \mathrm{~Hz}, 3 \mathrm{H})$.

2-Methylhexan-2-yl 2-bromothiophene-3-carboxylate (4). Compound 1 (3.12 g, 13.78 mmol) was added to a two-neck round bottom flask which was subsequently evacuated and refilled three times with argon. Anhydrous THF (10 mL) was added and the reaction flask was cooled to $-78^{\circ} \mathrm{C}$. LDA (2M in THF/heptane/ethylbenzene, $7.58 \mathrm{~mL}, 15.16 \mathrm{mmol}$ ) was added dropwise and the reaction was stirred for $1 \mathrm{~h}$ at $-78{ }^{\circ} \mathrm{C}$. To the reaction, $\mathrm{CBr}_{4}(5.03 \mathrm{~g}, 15.16 \mathrm{mmol})$ in anhydrous THF (7 $\mathrm{mL}$ ) was added. After $30 \mathrm{~min}$ at $-78^{\circ} \mathrm{C}$, the reaction was allowed to warm to room temperature and stirred overnight at room temperature. The solvent was removed under reduced pressure. The crude was purified through silica gel column chromatography with hexane:DCM =10:1 as eluent. Yielded a colorless liquid (2.86 g, $9.37 \mathrm{mmol}, 68 \%) .{ }^{1} \mathrm{H}$ NMR (400 MHz, $\left.\mathrm{CDCl}_{3}, \mathrm{ppm}\right): \delta=7.30$ (d, $J=5.8 \mathrm{~Hz}, 1 \mathrm{H}), 7.19$ (d, $J=5.8 \mathrm{~Hz}, 1 \mathrm{H}), 1.87$ (t, $J=7.8 \mathrm{~Hz}, 2 \mathrm{H}), 1.56(\mathrm{~s}, 6 \mathrm{H}), 1.31-1.40$ (m, 4H), $0.91(\mathrm{t}, J=7.0 \mathrm{~Hz}, 3 \mathrm{H})$.

DArP for P3ET synthesis. In a glove box under $\mathrm{N}_{2}$ atmosphere, a high-pressure flask was charged with $0.5 \mathrm{mmol}$ (152.6 mg) of compound 3 (for DArP-1) or compound 4 (for DArP-2), $\mathrm{PdCl}_{2}\left(\mathrm{PPh}_{3}\right)_{2}$ (21.1 mg, $\left.0.03 \mathrm{mmol}\right), \mathrm{P}(\mathrm{o}-\mathrm{MePh})_{3}$ (42.3 mg, $\left.0.12 \mathrm{mmol}\right)$, PivOH (25.5 mg, 0.25 $\mathrm{mmol}$ ), $\mathrm{Cs}_{2} \mathrm{CO}_{3}(244.4 \mathrm{mg}, 0.75 \mathrm{mmol}$ ) and anhydrous THF (2 mL). After securely sealed with a gastight cap, the reaction mixture was taken out of the glove box and stirred at $110^{\circ} \mathrm{C}$ for $20-40$ 
h. The reaction mixture was cooled to room temperature, then poured into methanol. The precipitate was collected via filtration, which was then purified by Soxhlet extraction with methanol, hexane, and chloroform. The chloroform fraction was concentrated under reduced pressure, and poured into methanol. The polymer was collected via filtration, which was then dried in a vacuum oven for $24 \mathrm{~h}$ at room temperature.

- Synthesis of P3ET, P3HT and RP-TCSs via Suzuki polycondensation<smiles>CC(C)(C)OC(=O)c1ccsc1Br</smiles>

4

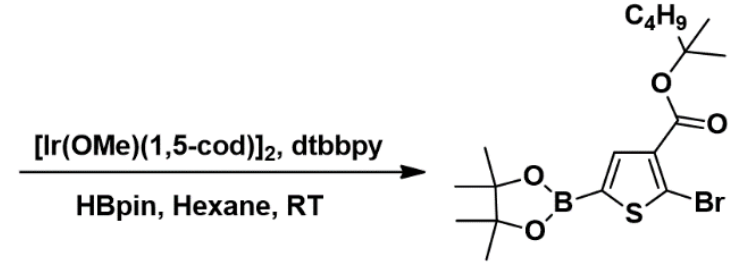

ET

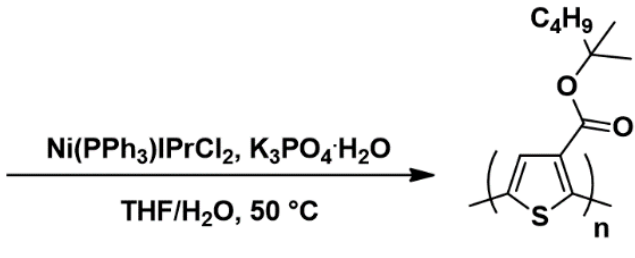

P3ET

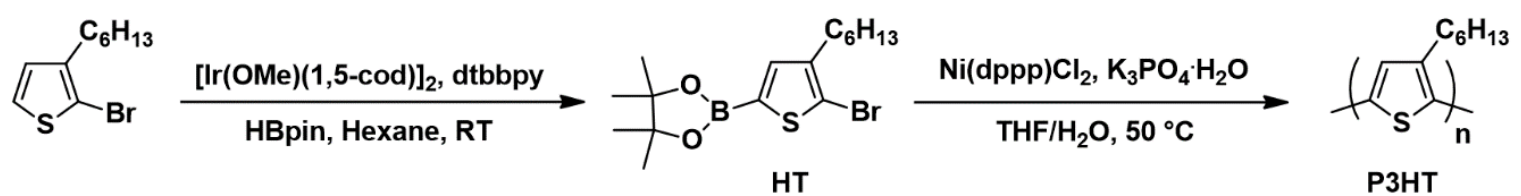<smiles>CC(C)(C)OC(=O)c1cc(B2OC(C)(C)C(C)(C)O2)sc1Br</smiles>

ET

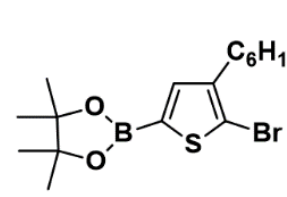

HT

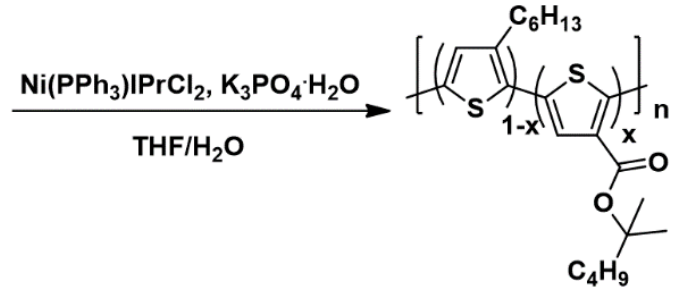

RP-TCS20 $(x=0.2)$ RP-TCS40 $(x=0.4)$ RP-TCS60 $(x=0.6)$ RP-TCS80 $(x=0.8)$

2-methylhexan-2-yl 2-bromo-5-(4,4,5,5-tetramethyl-1,3,2-dioxaborolan-2-yl)thiophene-3carboxylate (ET). Similar to previous literature. ${ }^{1}$ In a glove box under $\mathrm{N}_{2}$ atmosphere, a $40 \mathrm{~mL}$ scintillation vial was charged with pinacolborane (HBpin) (1.28 g, $10 \mathrm{mmol})$, di- $\mu$ methoxobis(1,5-cyclooctadiene)diiridium (49.7 $\mathrm{mg}, 0.075 \mathrm{mmol}$ ) and dry hexane $(4 \mathrm{~mL})$. To the reaction mixture, 4,4'-Bis(di-t-butyl)-2,2'-bipyridine (dtbbpy) (38.9 mg, $0.145 \mathrm{mmol}$ ) in hexane (4 $\mathrm{mL}$ ) was added, then the reaction mixture was stirred for $15 \mathrm{~min}$. Compound 4 (1.53 g, $5 \mathrm{mmol}$ ) dissolved in hexane $(4 \mathrm{~mL})$ was added to the reaction mixture slowly $\left(\mathrm{H}_{2}\right.$ gas evolves). The solution was stirred overnight in the glove box. The reaction was taken out of the glove box and loaded directly onto silica gel, then eluted with hexane:DCM $=1: 1$. The product was collected as a clear oil and slowly solidified after drying in vacuo to afford white powder (1.85 g, $4.3 \mathrm{mmol}$, 86 \%). ${ }^{1} \mathrm{H}$ NMR (400 MHz, $\left.\mathrm{CDCl}_{3}, \mathrm{ppm}\right): \delta=7.77$ (s, $\left.1 \mathrm{H}\right), 1.88$ (t, $\left.J=7.8 \mathrm{~Hz}, 2 \mathrm{H}\right), 1.54(\mathrm{~s}, 6 \mathrm{H})$, 1.30-1.40 (m, 16H), $0.91(\mathrm{t}, J=7.0 \mathrm{~Hz}, 3 \mathrm{H})$.

2-(5-bromo-4-hexylthiophen-2-yl)-4,4,5,5-tetramethyl-1,3,2-dioxaborolane (HT). Similar to previous literature. ${ }^{1}$ In a glove box under $\mathrm{N}_{2}$ atmosphere, a $40 \mathrm{~mL}$ scintillation vial was charged with pinacolborane (HBpin) (1.28 g, $10 \mathrm{mmol}$ ), di- $\mu$-methoxobis(1,5-cyclooctadiene)diiridium (49.7 mg, $0.075 \mathrm{mmol}$ ) and dry hexane $(4 \mathrm{~mL})$. To the reaction mixture, 4,4'-Bis(di-t-butyl)-2,2'- 
bipyridine (dtbbpy) (38.9 $\mathrm{mg}, 0.145 \mathrm{mmol}$ ) in hexane $(4 \mathrm{~mL})$ was added, then the reaction mixture was stirred for $15 \mathrm{~min}$. 2-Bromo-3-hexylthiophene (1.24 g, $5 \mathrm{mmol}$ ) dissolved in hexane (4 mL) was added to the reaction mixture slowly ( $\mathrm{H}_{2}$ gas evolves). The solution was stirred overnight in the glove box. The reaction was taken out of the glove box and loaded directly onto silica gel, then eluted with hexane:DCM = 1:1. The product was collected as a pale yellow oil $(1.77 \mathrm{~g}, 4.75 \mathrm{mmol}$, $86 \%$ ). ${ }^{1} \mathrm{H}$ NMR (400 MHz, $\left.\mathrm{CDCl}_{3}, \mathrm{ppm}\right): \delta=7.31$ (s, $\left.1 \mathrm{H}\right), 2.55$ (t, $\left.J=7.8 \mathrm{~Hz}, 2 \mathrm{H}\right), 1.57$ (q, $J=$ $7.3 \mathrm{~Hz}, 2 \mathrm{H}), 1.33$ (s, 12H), 1.30 (br, 6H), 0.88 (t, $J=7.0 \mathrm{~Hz}, 3 \mathrm{H})$.

General procedures for Suzuki polycondensation. Similar to previous literature. ${ }^{1}$ In a glove box under $\mathrm{N}_{2}$ atmosphere, a $20 \mathrm{~mL}$ scintillation vial was charged with $\mathrm{Ni}\left(\mathrm{PPh}_{3}\right) \mathrm{IPrCl}_{2}(23.4 \mathrm{mg}, 0.03$ $\mathrm{mmol}), \mathrm{K}_{3} \mathrm{PO}_{4} \cdot \mathrm{H}_{2} \mathrm{O}(397.2 \mathrm{mg}, 1.725 \mathrm{mmol})$ and anhydrous THF $(2 \mathrm{~mL})$. After securely sealed, the mixture was taken out of the glove box and stirred at room temperature under Argon. $1.5 \mathrm{mmol}$ of a monomer (646.8 $\mathrm{mg}$ of ET for P3ET synthesis, $559.7 \mathrm{mg}$ of $\mathbf{H T}$ for P3HT synthesis) dissolved in anhydrous THF $(2 \mathrm{~mL})$ was injected into the mixture followed by degassed $\mathrm{H}_{2} \mathrm{O}(0.1 \mathrm{~mL})$. Then, the reaction mixture was stirred at $50^{\circ} \mathrm{C}$. After $3 \mathrm{~h}$ of stirring, the reaction was quenched with 5 $\mathrm{M}$ methanolic $\mathrm{HCl}$. The precipitate was filtered and then purified by Soxhlet extraction with methanol, hexane, and chloroform. The chloroform fraction was concentrated under reduced pressure, and poured into methanol. The polymer was collected via filtration, which was then dried in a vacuum oven for $24 \mathrm{~h}$ at room temperature.

Suzuki polycondensation for RP-TCSs synthesis. Following the General procedures for Suzuki polycondensation described above with ET and HT in the appropriate monomer feed ratio at 1.5 mmol total monomer scale (e.g., $129.4 \mathrm{mg}(0.3 \mathrm{mmol})$ of $\mathbf{E T}$ and $411.8 \mathrm{mg}$ (1.2 mmol) of HT for RP-TCS20 synthesis). RP-TCS20 and RP-TCS80 were obtained from the chloroform fraction, while RP-TCS40 and RP-TCS60 were obtained from the hexane fraction after Soxhlet extraction. 
Scheme S1. Synthesis of P3ET via GRIM polymerization, DArP-1, DArP-2 and Suzuki polycondensation studied in this work.

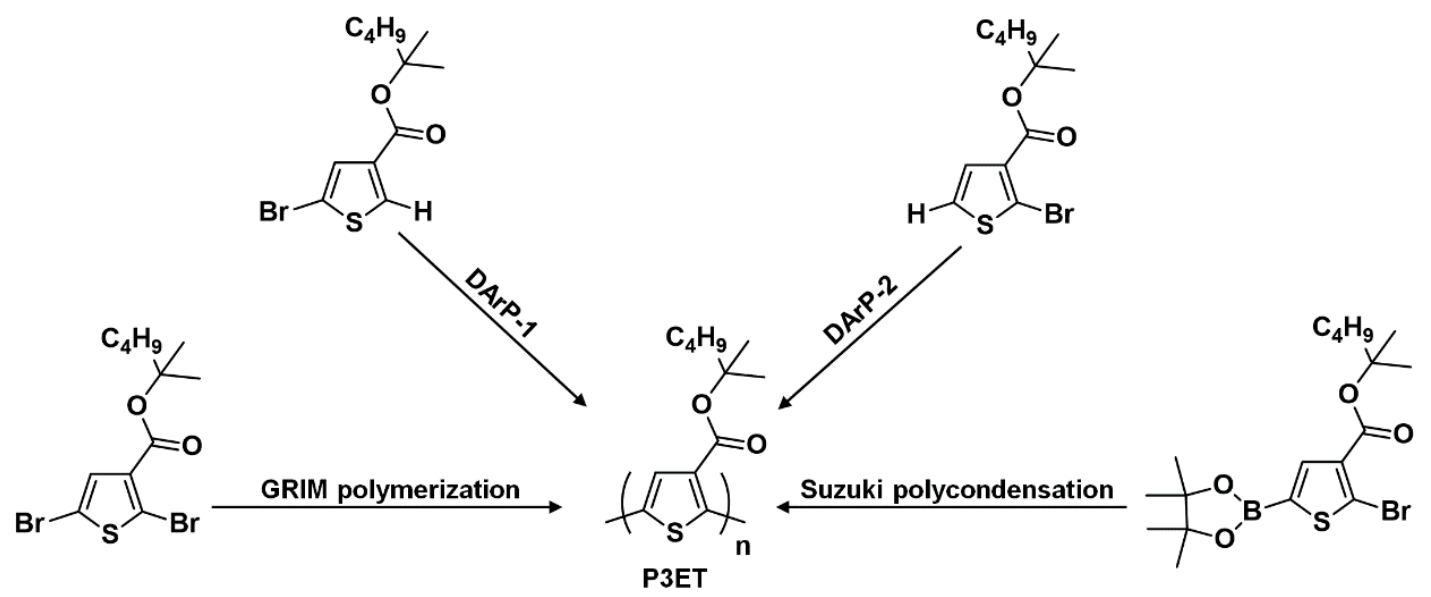

Scheme S2. Proposed mechanism for the synthesis of P3ET via nickel-mediated GRIM polymerization.
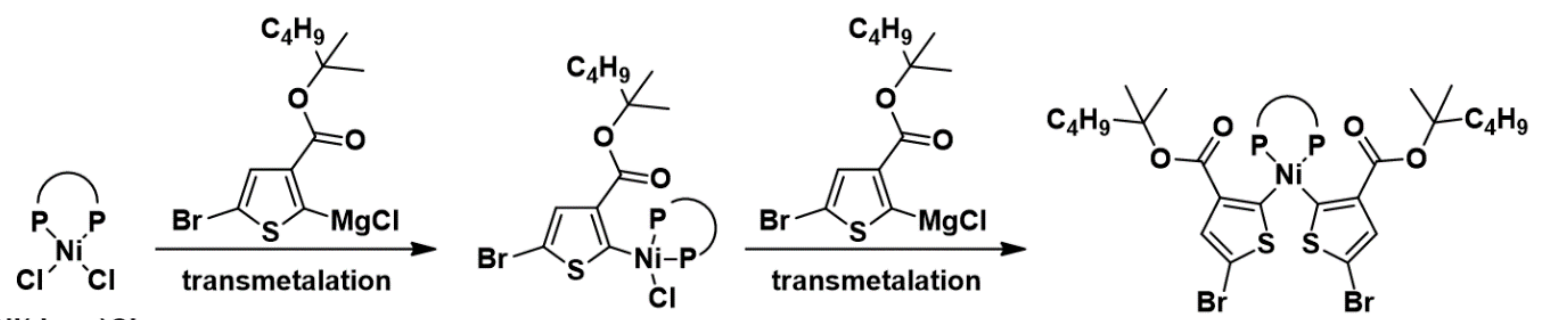
$\mathrm{Ni}(\mathrm{dppp}) \mathrm{Cl}_{2}$
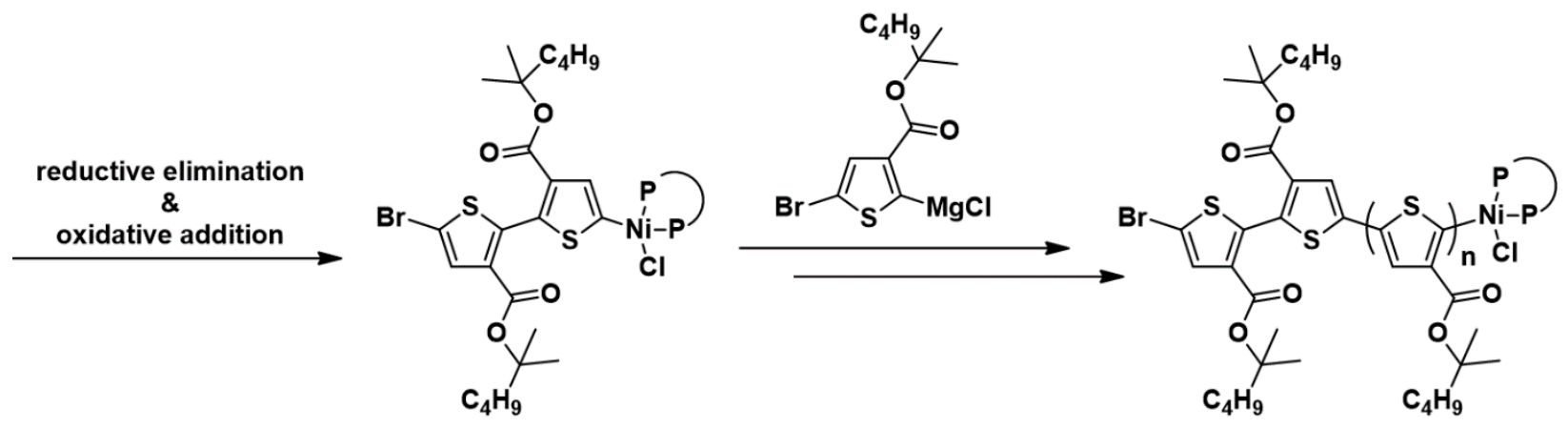
Figure S1. ${ }^{1} \mathrm{H}$ NMR spectrum of the reaction mixture after quenching the GRIM polymerization for synthesis of P3ET.

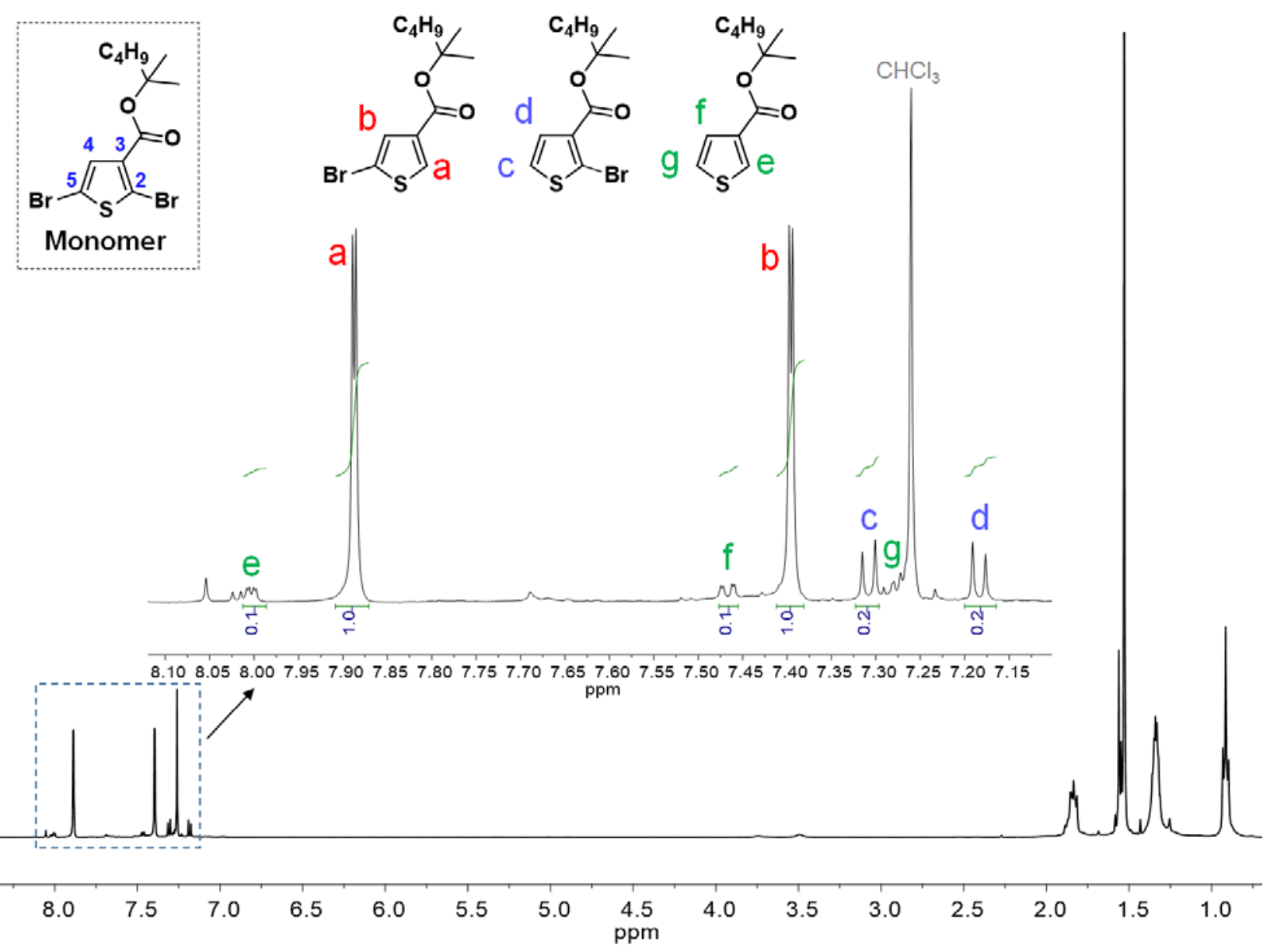


Figure S2. ${ }^{1} \mathrm{H}$ NMR spectrum of P3ET (Entry 1 in Table S2) synthesized via Suzuki polycondensation. 1,1,2,2-Tetrachloroethane_d $\mathrm{d}_{2}$ was used as a solvent. The spectrum was obtained at $60{ }^{\circ} \mathrm{C}$.

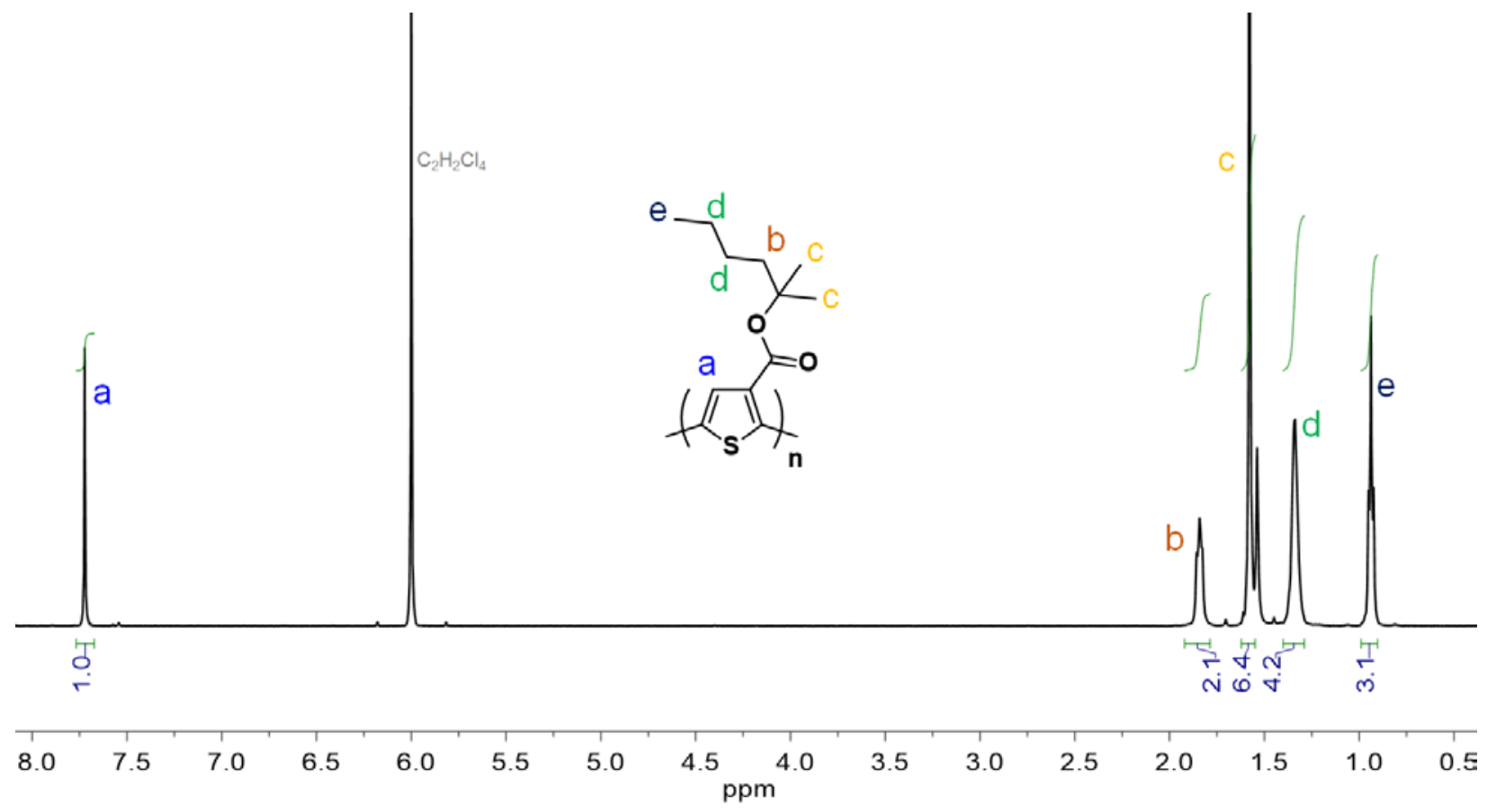

Figure S3. ${ }^{1} \mathrm{H}$ NMR spectrum of P3HT (Entry 4 in Table S3) synthesized via Suzuki polycondensation. 1,1,2,2-Tetrachloroethane_d $\mathrm{d}_{2}$ was used as a solvent. The spectrum was obtained at $60{ }^{\circ} \mathrm{C}$.

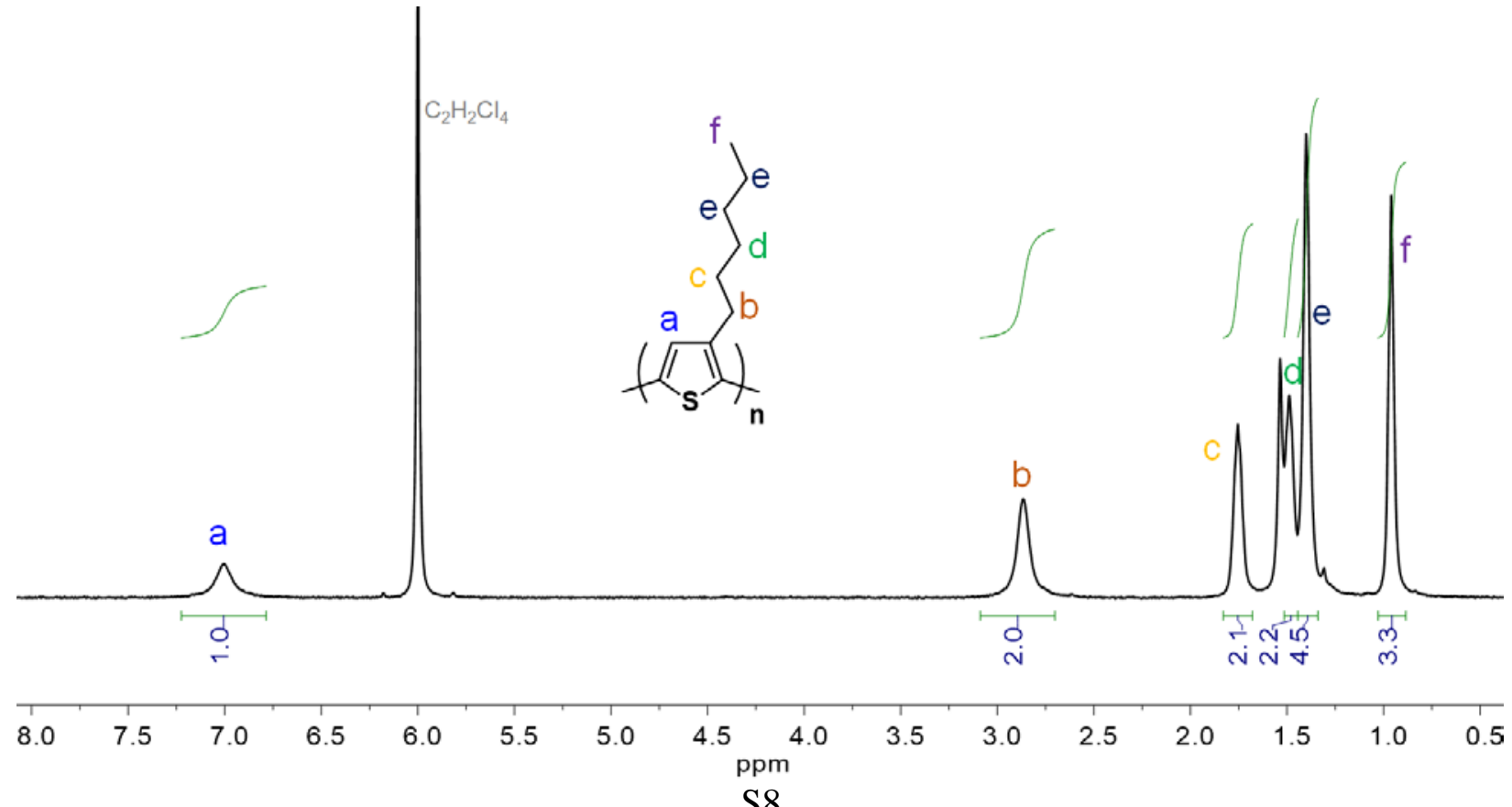


Figure S4. Storage modulus, loss modulus and $\tan (\delta)$ for the P3ET as-cast film and films annealed at $215^{\circ} \mathrm{C}$ for $10 \mathrm{~min}$ or $320^{\circ} \mathrm{C}$ for $10 \mathrm{~min}$.

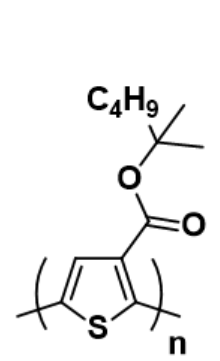

As-cast

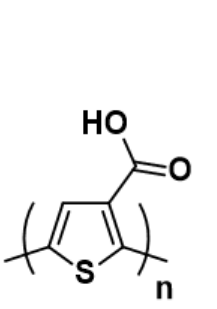

$215^{\circ} \mathrm{C}$ for $10 \mathrm{~min}$
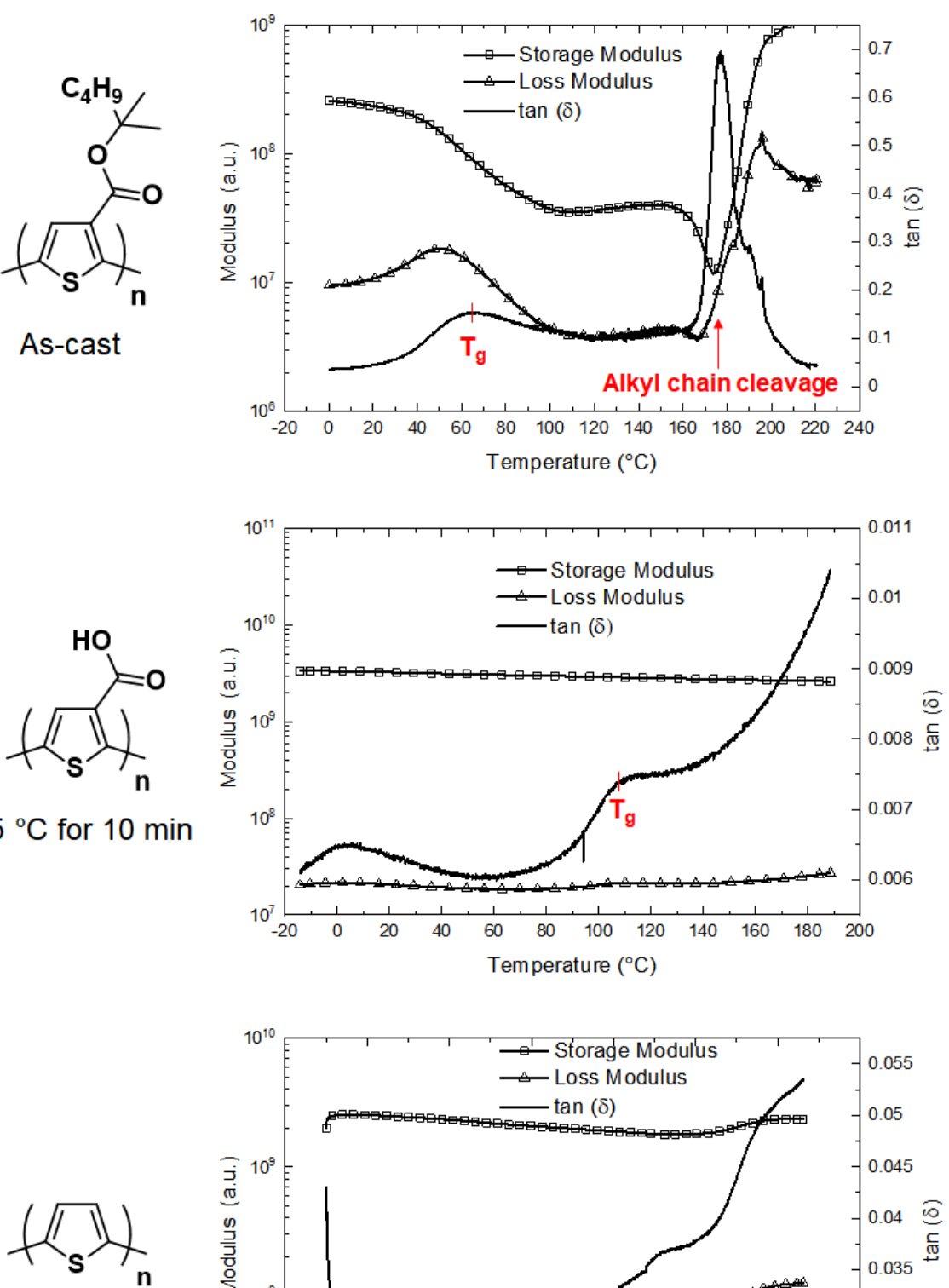

$320{ }^{\circ} \mathrm{C}$ for $10 \mathrm{~min}$

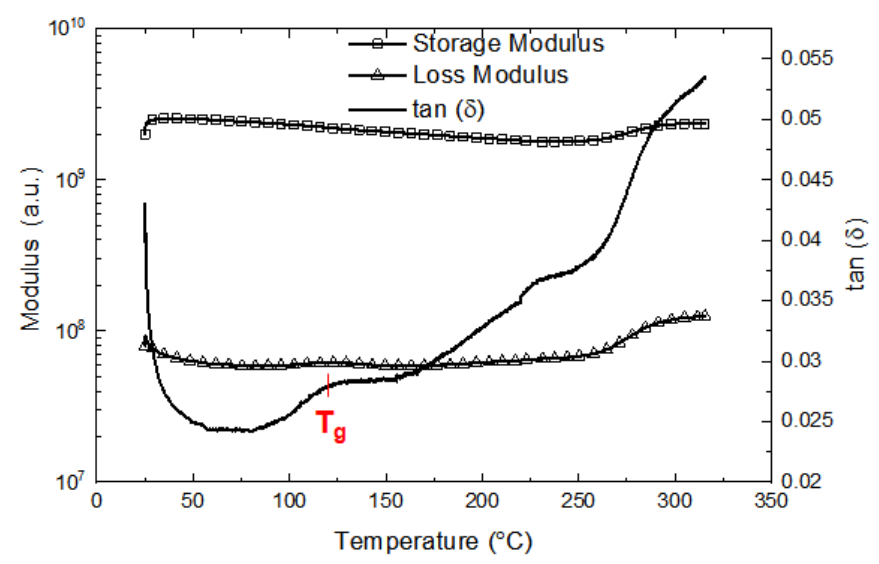


Figure S5. TGA of the precipitated insoluble polymer after heating P3ET solution at $150{ }^{\circ} \mathrm{C}$ for $10 \mathrm{~h}$. The polymer was thoroughly rinsed with acetone, then completely dried at room temperature prior to TGA. TGA was done at a heating rate of $10^{\circ} \mathrm{C} / \mathrm{min}$.

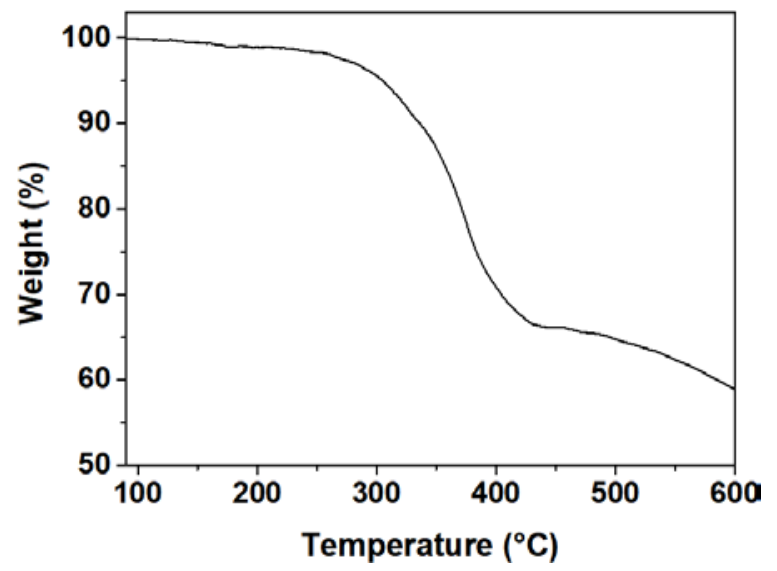

Figure S6. ${ }^{13} \mathrm{C}$ NMR spectrum of the of the filtrate obtained after removing the precipitated polymer.

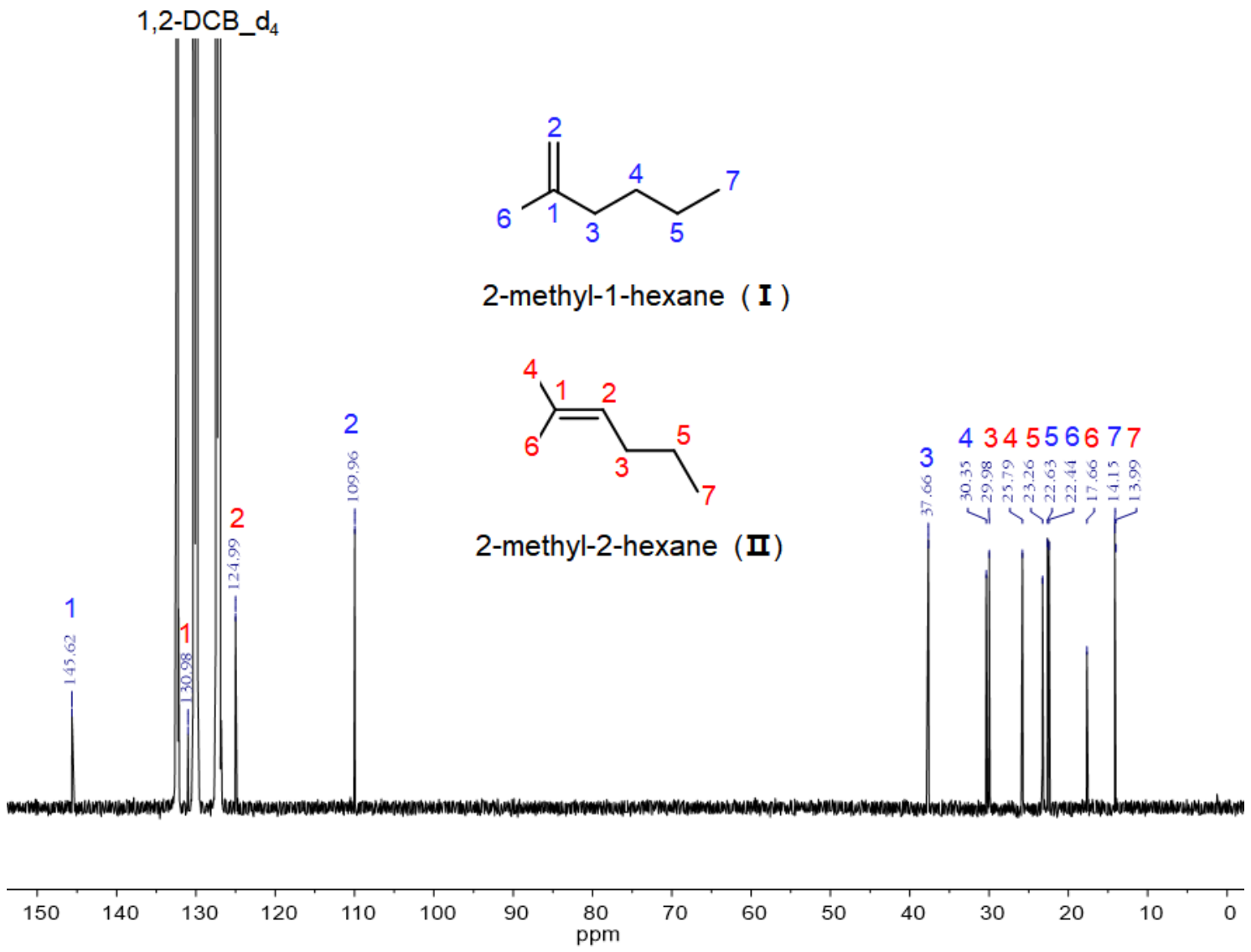


Figure S7. ${ }^{1} \mathrm{H}$ NMR spectra of P3ET solutions in 1,2-DCB-d 4 obtained after heating at each temperature for $24 \mathrm{hr}$.

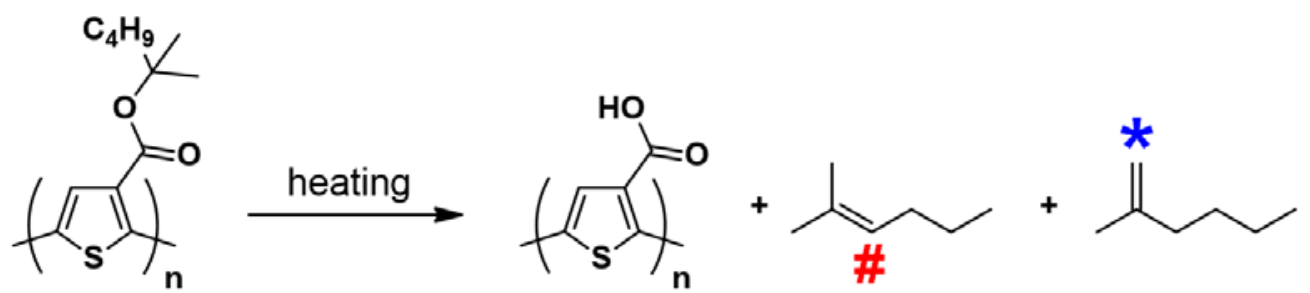

P3ET

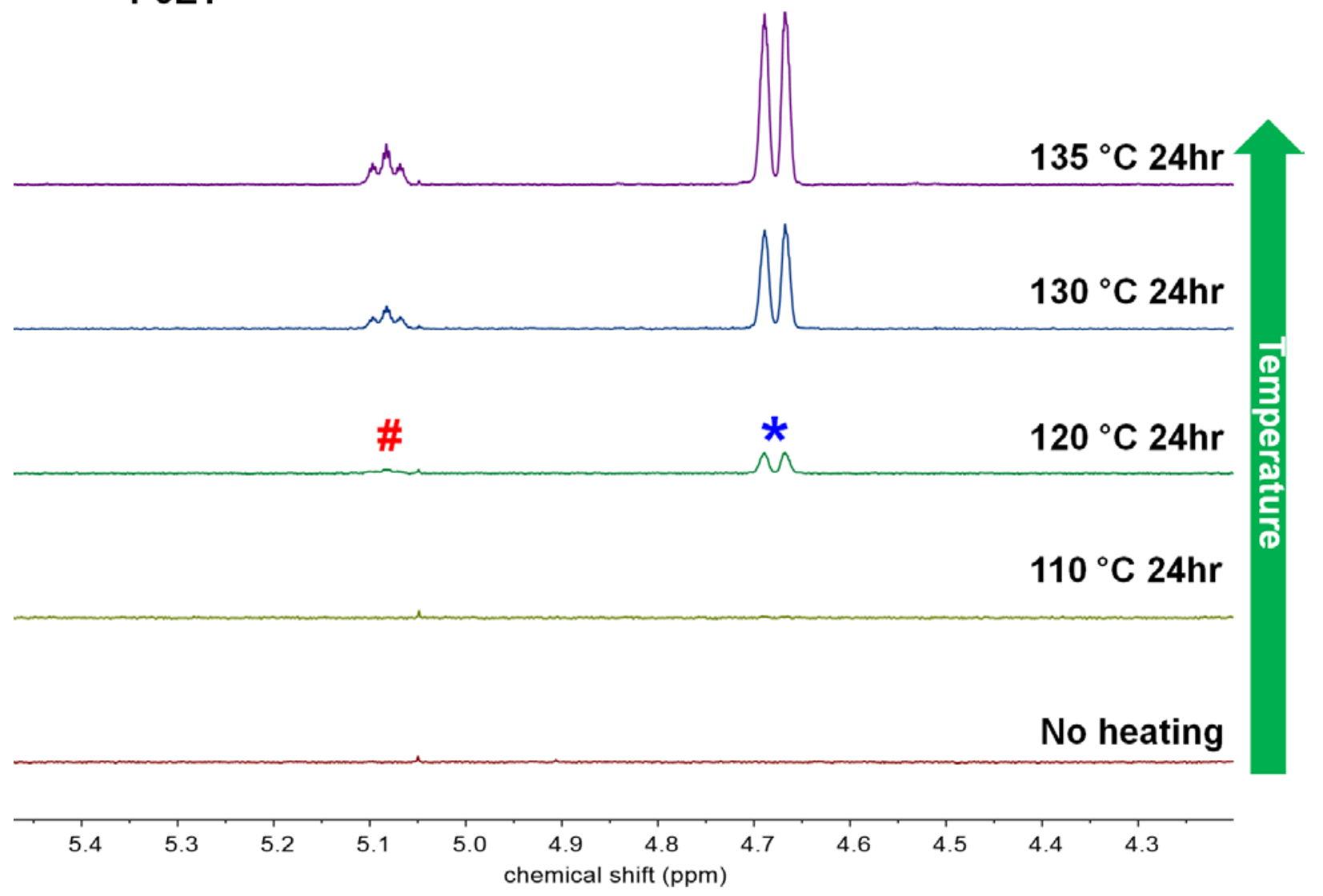


Figure S8. ${ }^{1} \mathrm{H}$ NMR spectrum of RP-TCS20. 1,1,2,2-Tetrachloroethane- $\mathrm{d}_{2}$ was used as a solvent. The spectrum was obtained at $60{ }^{\circ} \mathrm{C}$.

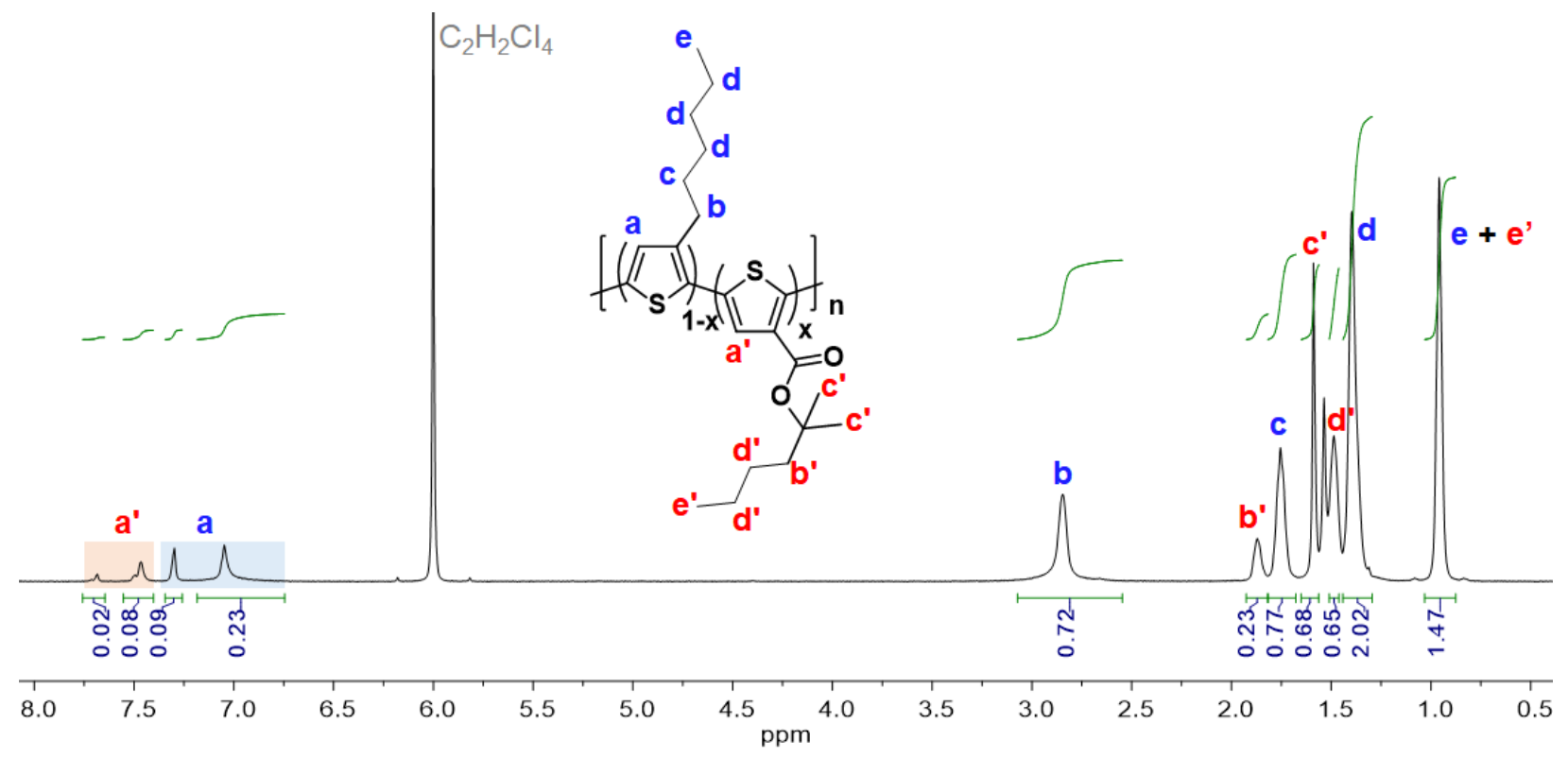

Figure S9. ${ }^{1} \mathrm{H}$ NMR spectrum of RP-TCS40. 1,1,2,2-Tetrachloroethane-d 2 was used as a solvent. The spectrum was obtained at $60^{\circ} \mathrm{C}$.

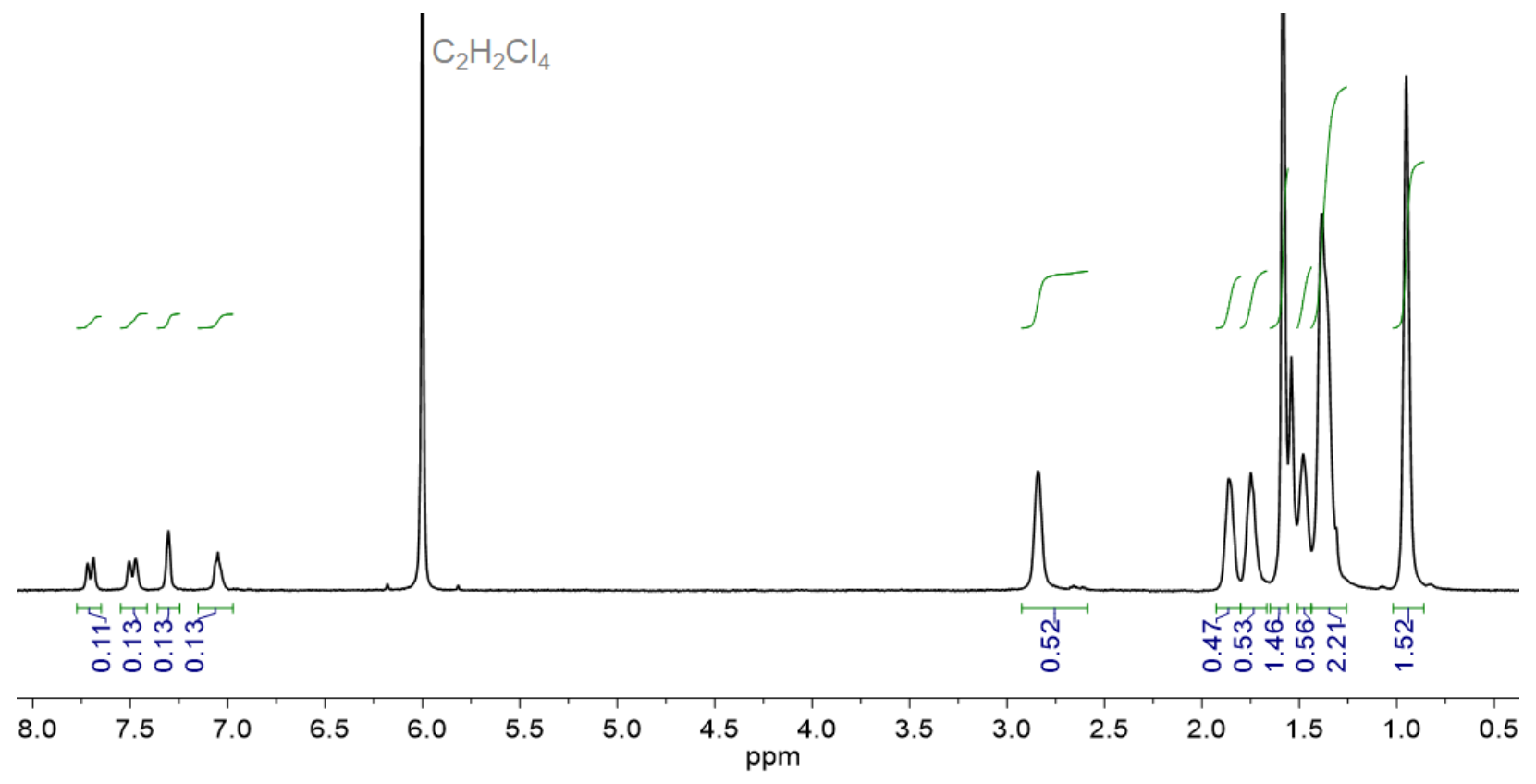


Figure S10. ${ }^{1} \mathrm{H}$ NMR spectrum of RP-TCS60. 1,1,2,2-Tetrachloroethane- $\mathrm{d}_{2}$ was used as a solvent. The spectrum was obtained at $60{ }^{\circ} \mathrm{C}$.

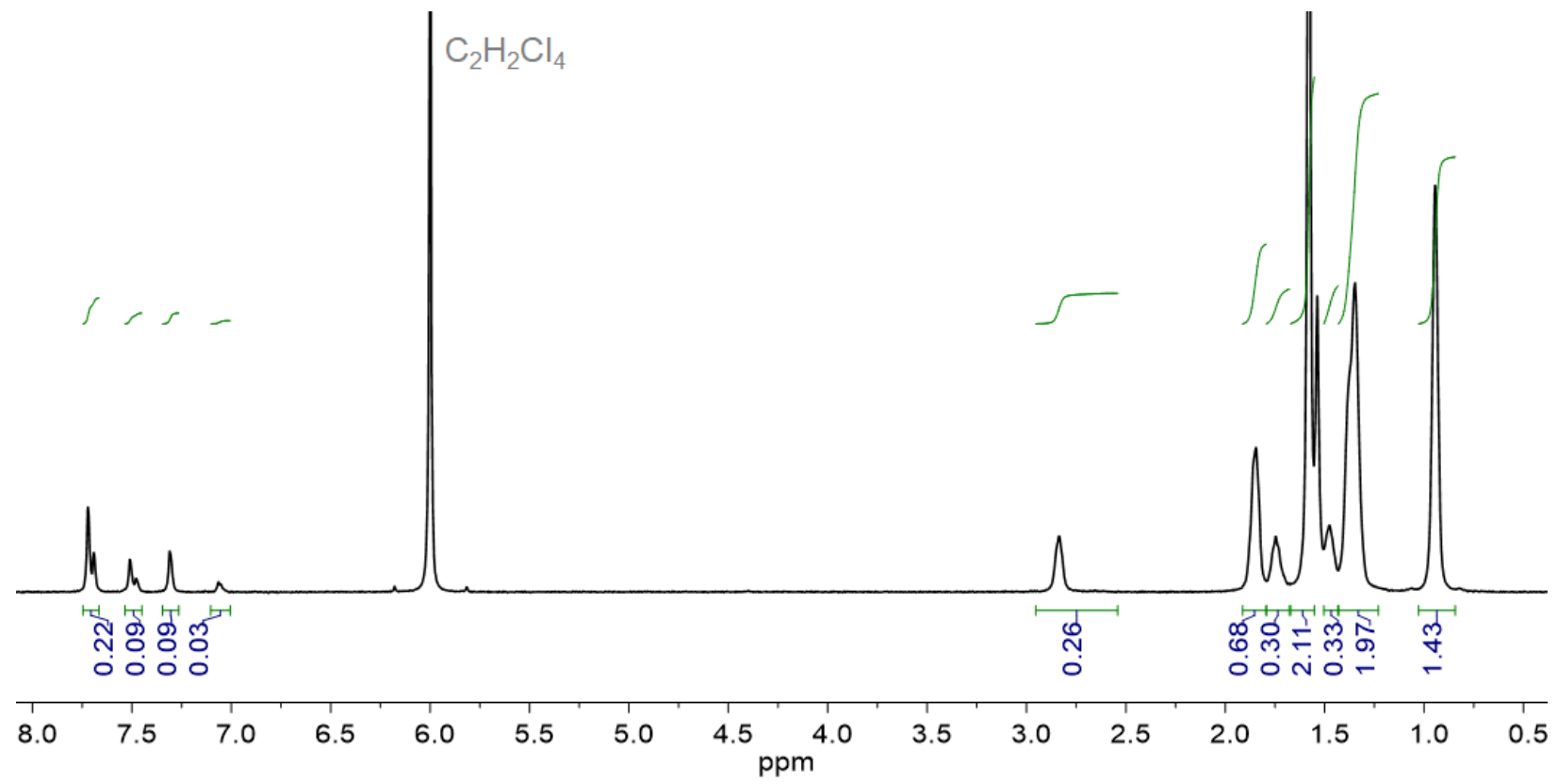

Figure S11. ${ }^{1} \mathrm{H}$ NMR spectrum of RP-TCS80. 1,1,2,2-Tetrachloroethane- $\mathrm{d}_{2}$ was used as a solvent. The spectrum was obtained at $60{ }^{\circ} \mathrm{C}$.

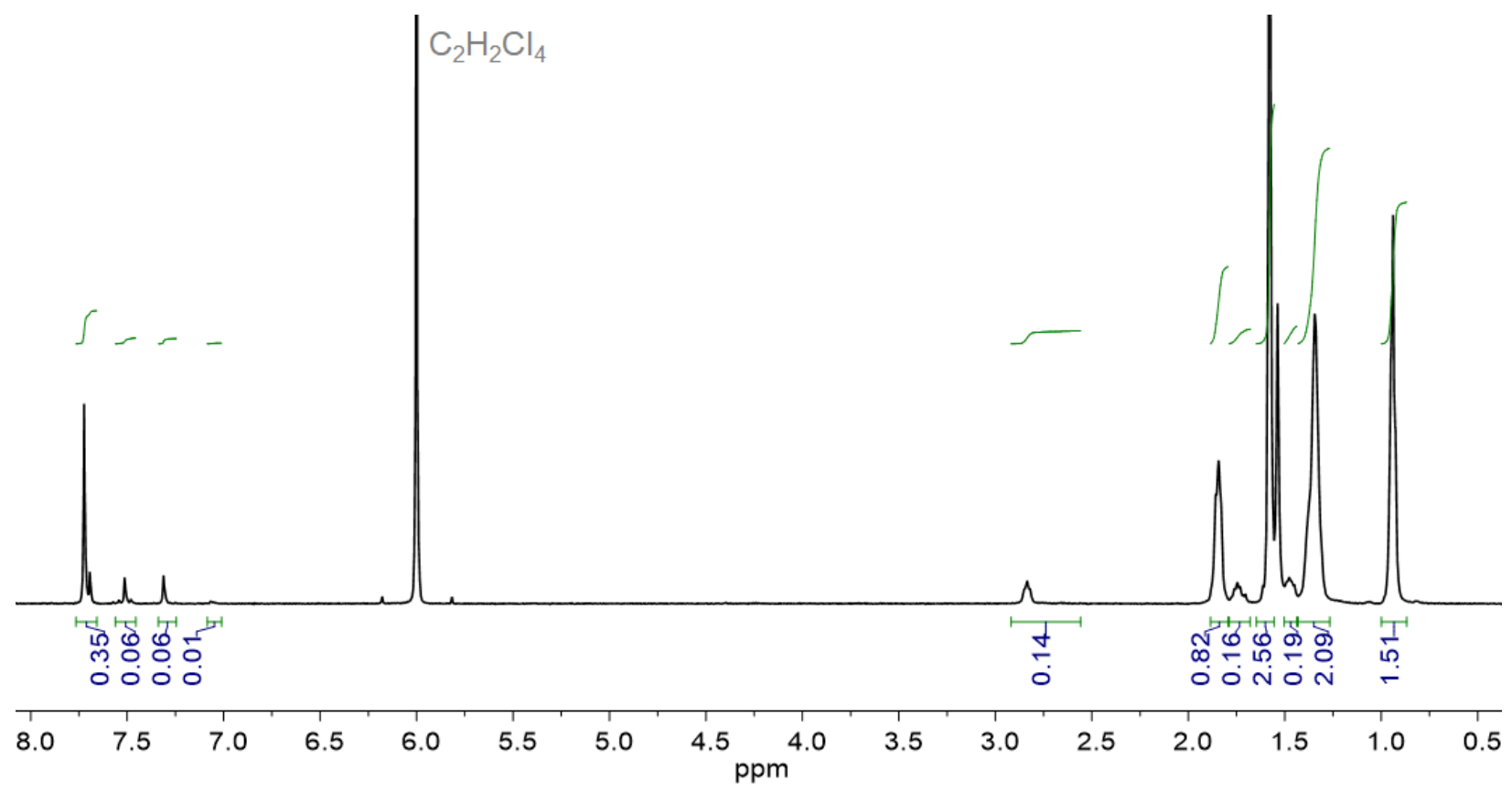


Figure S12. Storage modulus, loss modulus and tan $(\delta)$ of the polymers obtained via DMA for films cast and annealed at $100{ }^{\circ} \mathrm{C}$ for 1 minutes prior to the scan.
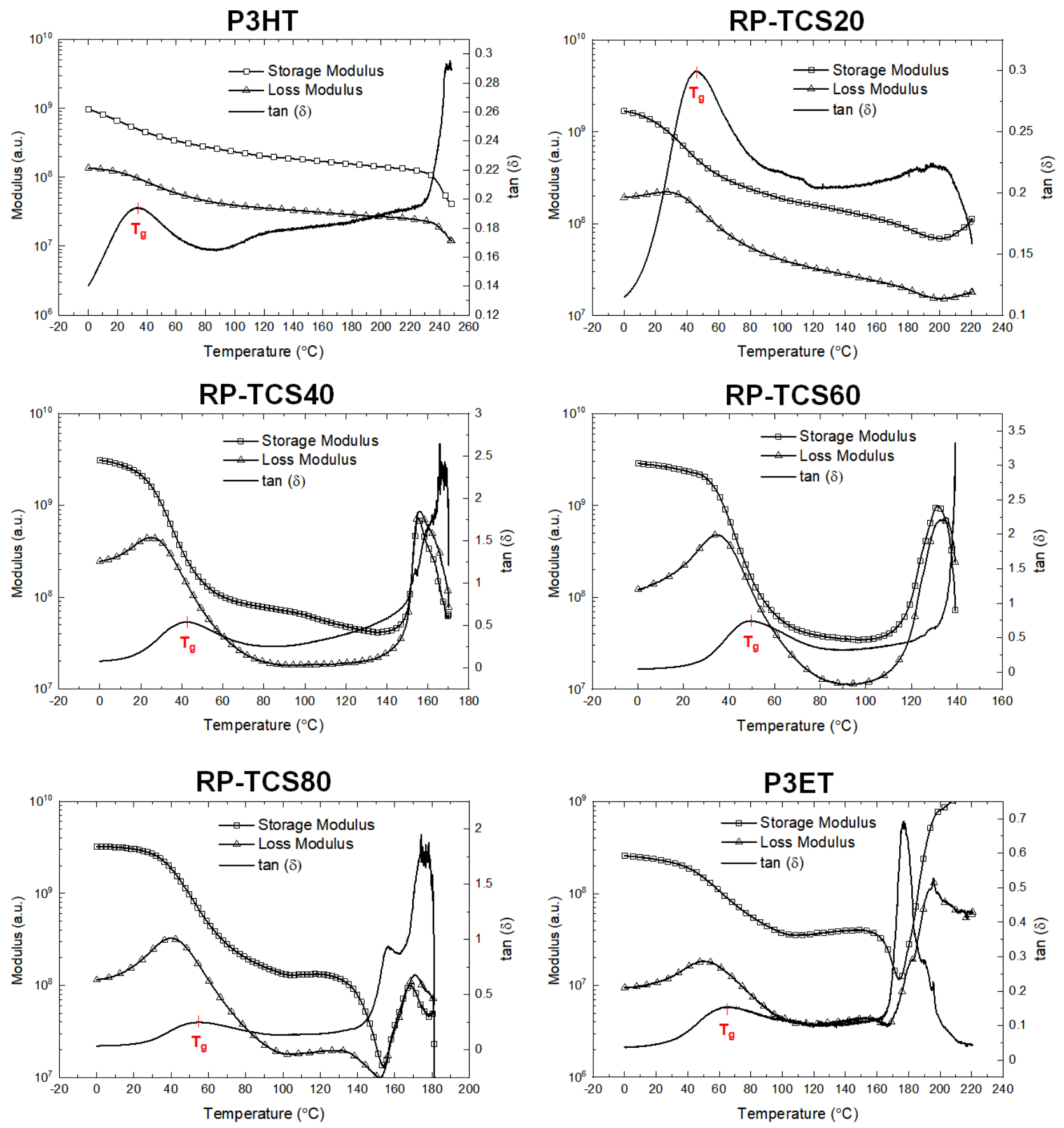
Figure S13. UV-vis absorption spectra of as-cast films before and after stability test (relative humidity $\sim 57 \%, 100{ }^{\circ} \mathrm{C}$, in air and in the dark for $24 \mathrm{~h}$ ).
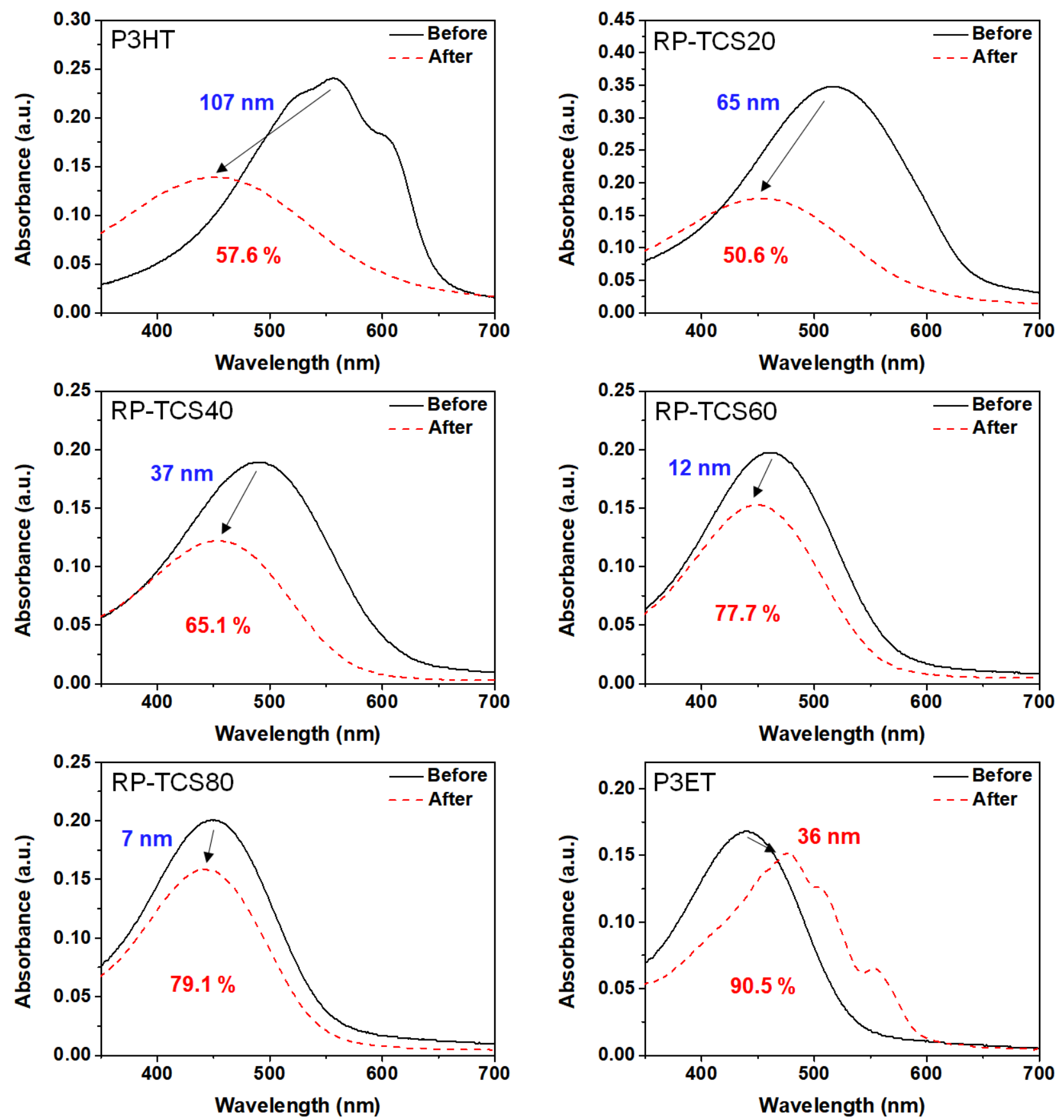
Figure S14. Photos of polymer films before (Day 0) and after the stability test (Day 1 and Day 7). The stability test condition: relative humidity $\sim 57 \%, 100{ }^{\circ} \mathrm{C}$, in air and under continuous ambient light.

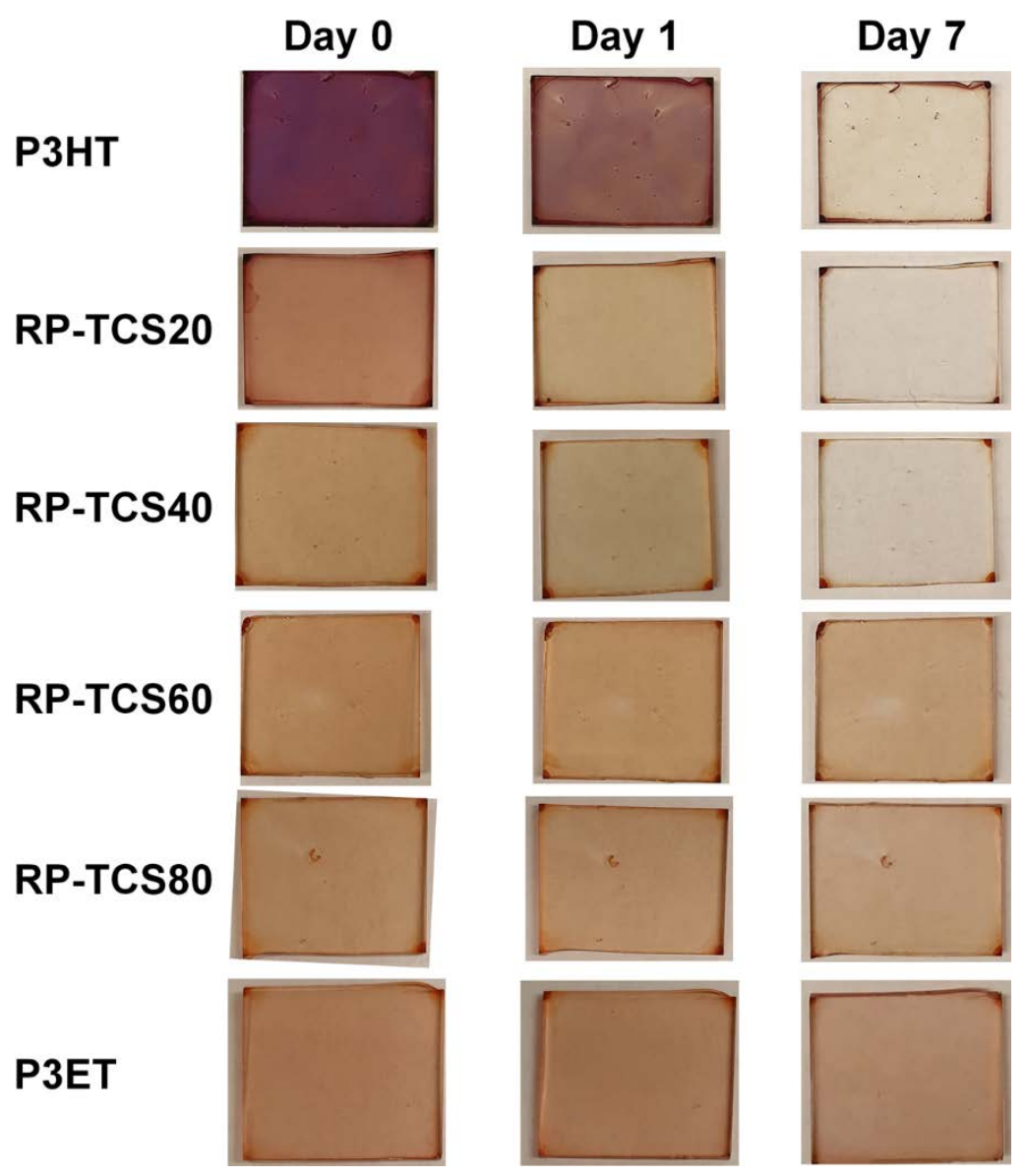


Figure S15. DSC thermograms of RP-TCS20, RP-TCS80 and P3ET at a heating and cooling rate of $10^{\circ} \mathrm{C} / \mathrm{min}$.
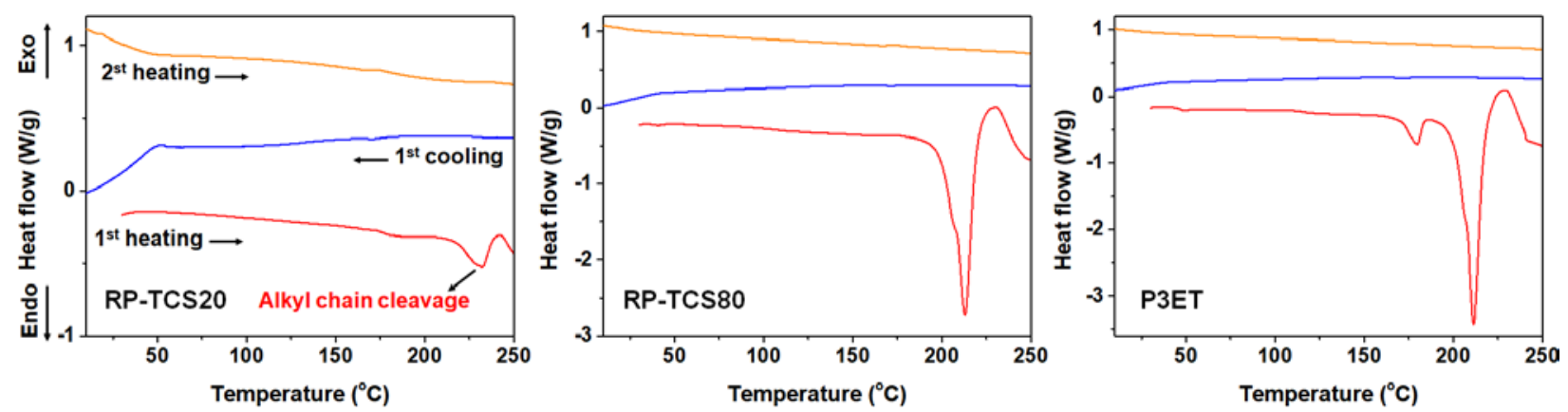

Figure S16. UV-vis absorption spectra of $200{ }^{\circ} \mathrm{C}$ annealed P3HT:P3ET blend films before and after the stability test (relative humidity $\sim 57 \%, 100{ }^{\circ} \mathrm{C}$, in air and under continuous ambient light for $24 \mathrm{~h}$ ).
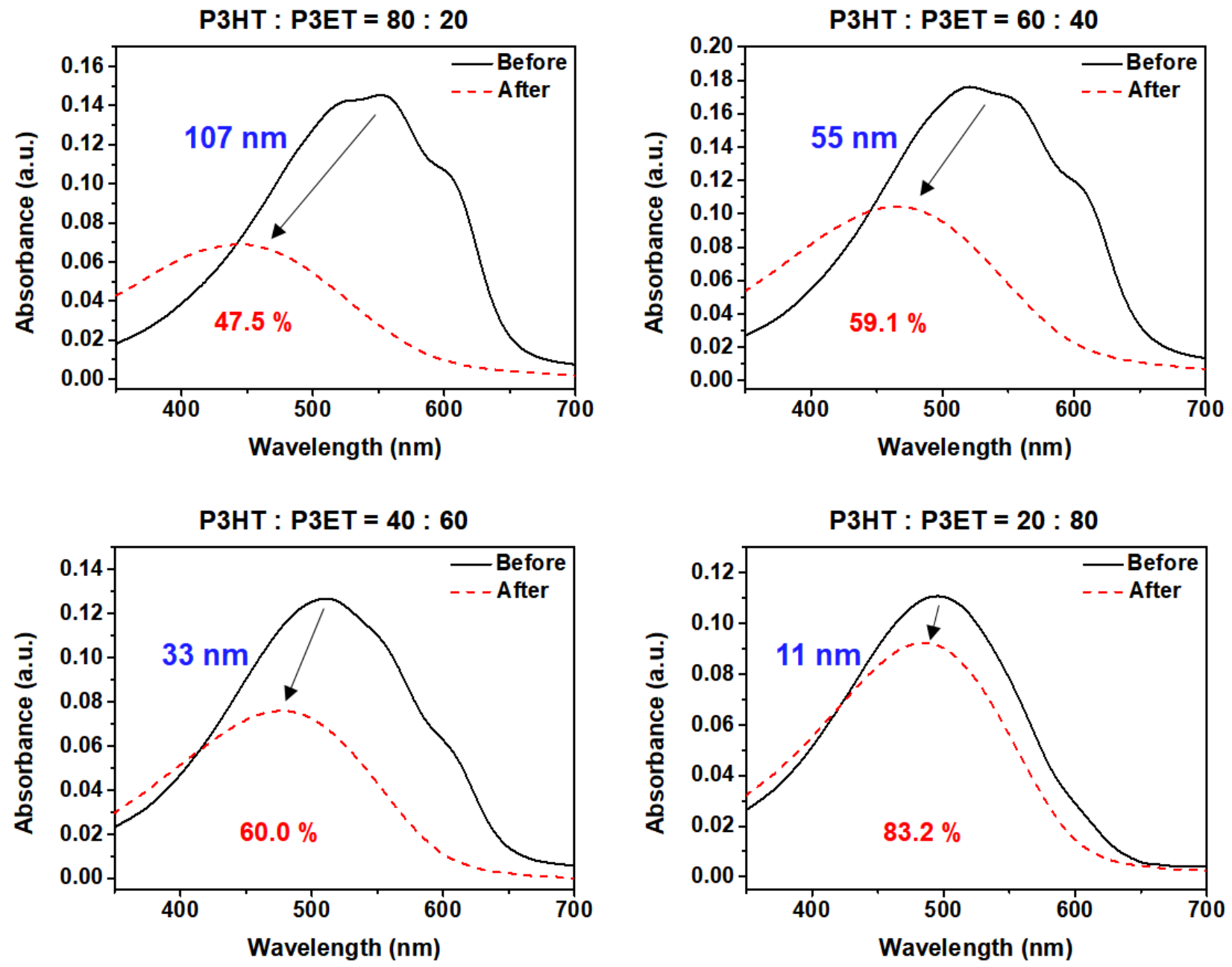
Figure S17. $J-V$ curves of the optimized PSCs based on polymer: $\mathrm{PC}_{61} \mathrm{BM}$ active layers after annealing at $200^{\circ} \mathrm{C}$ for $30 \mathrm{~min}$ (i.e., after thermocleavage of alkyl chains for RP-TCSs and P3ET).

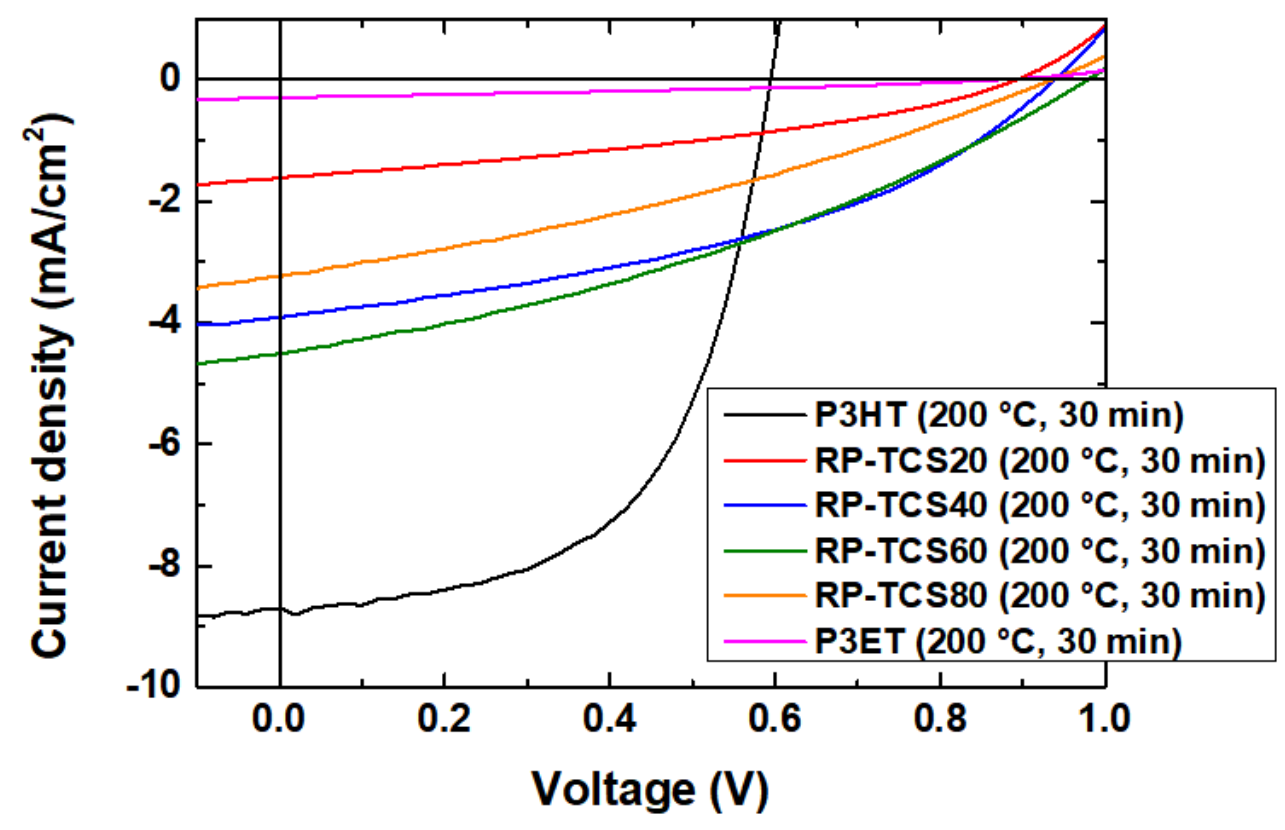


Figure S18. $J-V$ curves of the optimized PSCs based on polymer:PC ${ }_{61} \mathrm{BM}$ active layers after annealing at $110^{\circ} \mathrm{C}$ for $10 \mathrm{~min}$ (i.e., before thermocleavage of alkyl chains for RP-TCSs and P3ET).
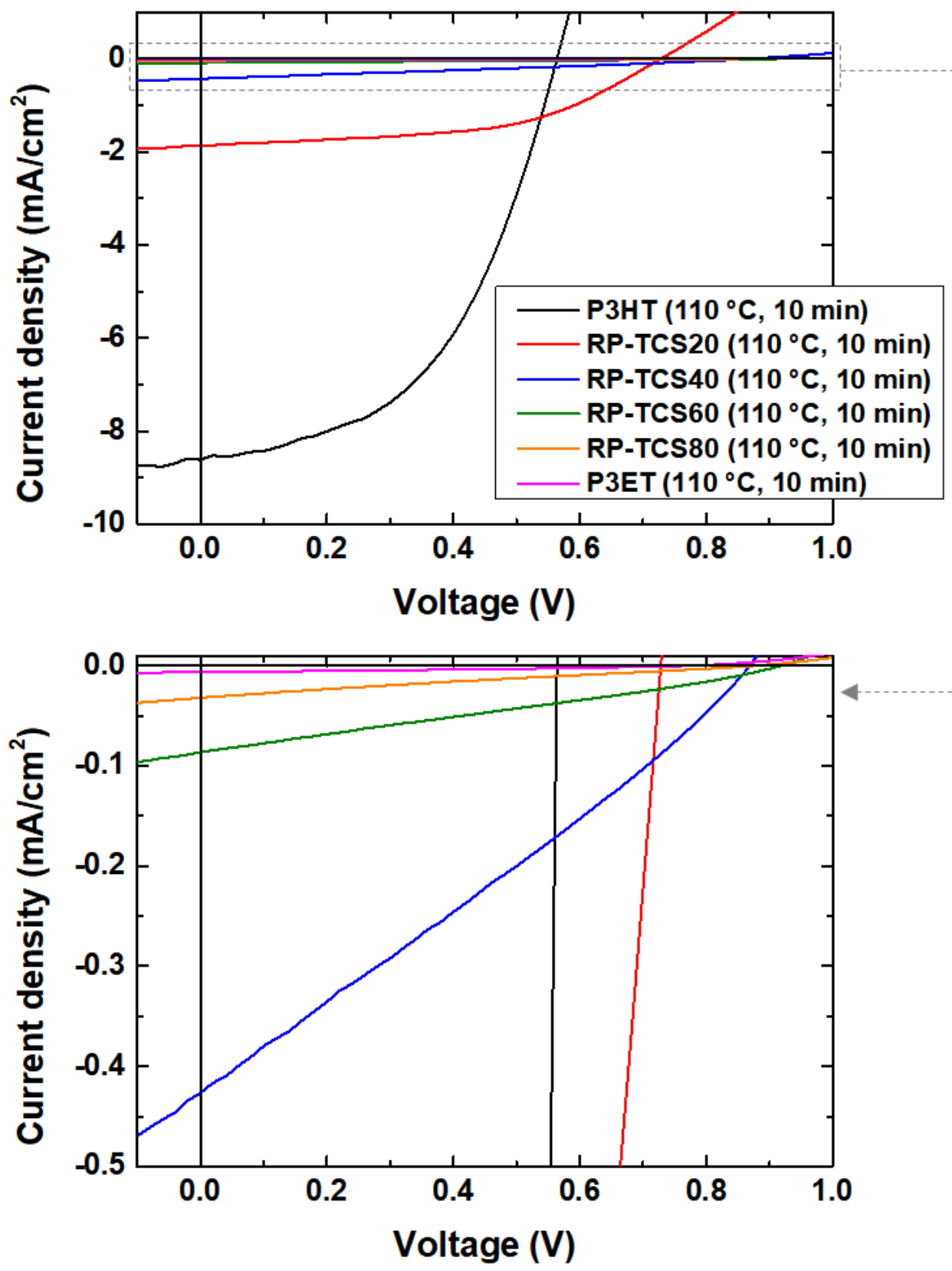
Table S1. Molecular weight, dispersity and yield of P3ET obtained via DArP-1 and DArP-2.

\begin{tabular}{cccccc}
\hline Entry & Polymerization & Polymerization time (h) & $M_{\mathrm{n}}{ }^{a}$ & $\bigoplus^{b}$ & Yield $^{c}$ (\%) \\
\hline 1 & DArP-1 & 20 & $6.3 \mathrm{~K}$ & 1.32 & 7 \\
\hline 2 & & 20 & $9.1 \mathrm{~K}$ & 1.39 & 77 \\
3 & DArP-2 & 40 & $11.4 \mathrm{~K}$ & 1.51 & 73 \\
\hline
\end{tabular}

${ }^{a}$ Number-average molecular weights and ${ }^{b}$ dispersity measured by GPC. ${ }^{c}$ Calculated from the chloroform fraction after Soxhlet extraction.

Table S2. Molecular weight, dispersity and yield of P3ET obtained via Suzuki polycondensation.

\begin{tabular}{ccccc}
\hline Entry & Catalyst & $M_{\mathrm{n}}{ }^{a}$ & $\oplus^{b}$ & Yield $^{c}$ (\%) \\
\hline 1 & $\mathrm{Ni}_{\left(\mathrm{PPh}_{3}\right) \mathrm{IPrCl}_{2}}$ & $56.7 \mathrm{~K}$ & 1.55 & 89 \\
2 & & $84.1 \mathrm{~K}$ & 1.32 & 91 \\
\hline 3 & $\mathrm{Ni}(\mathrm{dppp}) \mathrm{Cl}_{2}$ & $12.5 \mathrm{~K}$ & 1.07 & 23 \\
\hline
\end{tabular}

${ }^{a}$ Number-average molecular weights and ${ }^{b}$ dispersity measured by GPC. ${ }^{c}$ Calculated from the chloroform fraction after Soxhlet extraction.

Table S3. Molecular weight, dispersity and yield of P3HT obtained via Suzuki polycondensation.

\begin{tabular}{ccccc}
\hline Entry & Catalyst & $M_{\mathrm{n}}{ }^{a}$ & $\Xi^{b}$ & Yield $^{c}(\%)$ \\
\hline 1 & $\mathrm{Ni}\left(\mathrm{PPh}_{3}\right) \mathrm{IPrCl}_{2}$ & $23.0 \mathrm{~K}$ & 1.74 & 50 \\
2 & & $35.1 \mathrm{~K}$ & 1.74 & 55 \\
\hline 3 & \multirow{2}{*}{$\mathrm{Ni}(\mathrm{dppp}) \mathrm{Cl}_{2}$} & $36.7 \mathrm{~K}$ & 1.17 & 65 \\
4 & & $37.7 \mathrm{~K}$ & 1.29 & 70 \\
\hline
\end{tabular}

${ }^{a}$ Number-average molecular weights and ${ }^{b}$ dispersity measured by GPC. ${ }^{c}$ Calculated from the chloroform fraction after Soxhlet extraction. 
Table S4. Summary of photovoltaic parameters for PSCs based on polymer:PC ${ }_{61} \mathrm{BM}$ active layers. Measurements were performed under AM 1.5G solar illumination.

\begin{tabular}{|c|c|c|c|c|c|c|}
\hline Polymer & $\begin{array}{l}\text { Ann. } \\
\text { condition }\end{array}$ & Thickness [nm] & $J_{\mathrm{SC}} \pm \sigma$ & $V_{\mathrm{OC}} \pm \sigma$ & $\mathrm{FF} \pm \sigma[\%]$ & PCE $\pm \sigma$ (best) $[\%]$ \\
\hline \multirow{2}{*}{ Р3HT } & $\begin{array}{c}110^{\circ} \mathrm{C}, 10 \\
\min \end{array}$ & $242.5 \pm 34.6$ & $6.94 \pm 1.28$ & $0.57 \pm 0.01$ & $40.4 \pm 5.9$ & $1.62 \pm 0.51(2.40)$ \\
\hline & $\begin{array}{c}200{ }^{\circ} \mathrm{C}, 30 \\
\mathrm{~min}\end{array}$ & $258.2 \pm 13.3$ & $8.20 \pm 0.35$ & $0.59 \pm 0.00$ & $54.4 \pm 3.6$ & $2.1 \pm 0.27$ (2.97) \\
\hline \multirow{2}{*}{ RP-TCS20 } & $\begin{array}{c}110^{\circ} \mathrm{C}, 10 \\
\min \end{array}$ & $194.2 \pm 14.65$ & $1.58 \pm 0.30$ & $0.74 \pm 0.01$ & $49.2 \pm 3.9$ & $0.58 \pm 0.14(0.70)$ \\
\hline & $\begin{array}{c}200^{\circ} \mathrm{C}, 30 \\
\text { min }\end{array}$ & $187.94 \pm 16.44$ & $1.54 \pm 0.05$ & $0.89 \pm 0.01$ & $35.5 \pm 0.1$ & $0.488 \pm 0.019(0.510)$ \\
\hline \multirow{2}{*}{ RP-TCS40 } & $\begin{array}{c}110^{\circ} \mathrm{C}, 10 \\
\min \end{array}$ & $185.3 \pm 15.87$ & $0.39 \pm 0.03$ & $0.85 \pm 0.05$ & $27.2 \pm 1.0$ & $0.09 \pm 0.01(0.10)$ \\
\hline & $\begin{array}{c}200^{\circ} \mathrm{C}, 30 \\
\min \end{array}$ & $180.27 \pm 12.85$ & $3.59 \pm 0.35$ & $0.93 \pm 0.01$ & $39.4 \pm 1.1$ & $1.315 \pm 0.167(1.480)$ \\
\hline \multirow{2}{*}{ RP-TCS60 } & $\begin{array}{c}110^{\circ} \mathrm{C}, 10 \\
\text { min }\end{array}$ & $182.6 \pm 11.68$ & $0.08 \pm 0.00$ & $0.89 \pm 0.05$ & $27.0 \pm 0.4$ & $0.02 \pm 0.00(0.02)$ \\
\hline & $\begin{array}{c}200^{\circ} \mathrm{C}, 30 \\
\text { min }\end{array}$ & $56.19 \pm 5.58$ & $4.10 \pm 0.35$ & $0.95 \pm 0.07$ & $32.7 \pm 3.6$ & $1.264 \pm 0.201(1.500)$ \\
\hline \multirow{2}{*}{ RP-TCS80 } & $\begin{array}{c}110^{\circ} \mathrm{C}, 10 \\
\text { min }\end{array}$ & $92.5 \pm 7.84$ & $0.03 \pm 0.00$ & $0.87 \pm 0.00$ & $23.0 \pm 0.1$ & $0.01 \pm 0.00(0.01)$ \\
\hline & $\begin{array}{c}200{ }^{\circ} \mathrm{C}, 30 \\
\text { min }\end{array}$ & $76.78 \pm 36.04$ & $2.94 \pm 0.35$ & $0.89 \pm 0.06$ & $31.0 \pm 2.4$ & $0.813 \pm 0.126(0.960)$ \\
\hline \multirow{2}{*}{ P3ET } & $\begin{array}{c}110^{\circ} \mathrm{C}, 10 \\
\min \end{array}$ & $215.7 \pm 23.03$ & $0.01 \pm 0.00$ & $0.76 \pm 0.03$ & $28.2 \pm 8.7$ & $0.001 \pm 0.000(0.002)$ \\
\hline & $\begin{array}{c}200^{\circ} \mathrm{C}, 30 \\
\text { min }\end{array}$ & $98.9 \pm 4.88$ & $0.28 \pm 0.02$ & $0.87 \pm 0.01$ & $36.0 \pm 10.6$ & $0.09 \pm 0.03(0.14)$ \\
\hline
\end{tabular}

\section{References}

1. Qiu, Y.; Worch, J. C.; Fortney, A.; Gayathri, C.; Gil, R. R.; Noonan, K. J. Nickel-catalyzed suzuki polycondensation for controlled synthesis of ester-functionalized conjugated polymers. Macromolecules, 2016, 49, 4757. 